FEDERAL RESERVE BANK OF SAN FRANCISCO

WORKING PAPER SERIES

\title{
Endogenous Forecast Switching Near the Zero Lower Bound
}

\author{
Kevin J. Lansing \\ Federal Reserve Bank of San Francisco
}

December 2019

Working Paper 2017-24

http://www.frbsf.org/economic-research/publications/working-papers/2017/24/

\section{Suggested citation:}

Kevin J. Lansing. 2019. "Endogenous Forecast Switching Near the Zero Lower Bound,” Federal Reserve Bank of San Francisco Working Paper 2017-24. https://doi.org/10.24148/wp2017-24

The views in this paper are solely the responsibility of the authors and should not be interpreted as reflecting the views of the Federal Reserve Bank of San Francisco or the Board of Governors of the Federal Reserve System. 


\title{
Endogenous Forecast Switching Near the Zero Lower Bound*
}

\author{
Kevin J. Lansing ${ }^{\dagger}$ \\ Federal Reserve Bank of San Francisco
}

December 10, 2019

\begin{abstract}
A representative agent contemplates the possibility of an occasionally binding zero lower bound (ZLB) on the nominal interest rate that is driven by switching between two local equilibria, labeled the "targeted" and "deflation" solutions, respectively. This view turns out to be true in simulations, thus validating the agent's beliefs. I solve for the time series of stochastic shocks and endogenous forecast weights that allow the model to exactly replicate the observed time paths of U.S. data since 1988. The data since the start of the ZLB episode in 2008.Q4 are best described as a time-varying mixture of the two local equilibria.

Keywords: Natural rate of interest, Liquidity trap, Zero lower bound, Taylor rule, Deflation.
\end{abstract}

JEL Classification: E31, E43, E52.

${ }^{*}$ Forthcoming, Journal of Monetary Economics. An earlier version of this paper was titled "Endogenous Regime Switching Near the Zero Lower Bound." The views in this paper are my own and not necessarily those of the Federal Reserve Bank of San Francisco or the Board of Governors of the Federal Reserve System. For helpful comments and suggestions, I thank Boroğan Aruoba, James Bullard, James Costain, Pablo CubaBorda, Gavin Goy, Hervé Le Bihan, Giovanni Ricco, Stephanie Schmitt-Grohé, Sanjay Singh, Roman Šustek, and conference/seminar participants at FRB Cleveland, Bank of Japan, UC Riverside, the 2017 AEA Meeting, the 2017 SNDE Symposium, the 2017 Monash University Macro-Finance Workshop, the 2017 Bank of England conference on "Applications of Behavioral Economics and Multiple Equilibria to Macroeconomic Policy," the 2017 Conference on "Expectations in Dynamic Macroeconomic Models," hosted by FRB St. Louis, the 2017 Vienna Macroeconomics Workshop, the 2018 Norges Bank Conference on "Nonlinear Models in Macroeconomics and Finance," the 20th Annual (2018) Inflation Targeting Conference of the Banco Central do Brasil, the 2018 Banca d'Italia-CEPR Conference on Money, Banking, and Finance, and the 2019 CEBRA Annual Meeting.

${ }^{\dagger}$ Federal Reserve Bank of San Francisco, P.O. Box 7702, San Francisco, CA 94120-7702, email: kevin.j.lansing@sf.frb.org 


\section{Introduction}

The sample period from 1988 onwards is generally viewed as an example of consistent U.S. monetary policy aimed at keeping inflation low while promoting sustainable growth and full employment. Amazingly, the U.S. federal funds rate was pinned close to zero for 7 consecutive years during this period. The U.S. economy is not alone in experiencing an extended period of zero or mildly negative nominal interest rates in recent decades. Short-term nominal interest rates in Japan have remained near zero since 1998.Q3 except for the relatively brief period from 2006.Q4 to 2008.Q3. Short-term nominal interest rates in Switzerland and the United Kingdom have been close to zero or slightly negative since 2009.Q1. Outside of these episodes, all four countries exhibit a strong positive correlation between nominal interest rates and inflation, consistent with the Fisher relationship.

Benhabib, Schmitt-Grohé, and Uribe (2001a,b) show that imposing a zero lower bound (ZLB) on the nominal interest rate in a standard New Keynesian model gives rise to two long-run endpoints (steady states). ${ }^{1}$ The basic idea is illustrated in Figure 1 which is adapted from Bullard (2010). Using data from 1922.Q1 to 2017.Q4, the figure plots the 4-quarter CPI inflation rate versus the nominal three-month Treasury bill yield. Nominal Treasury yields encountered the ZLB during the 1930s and from 2008.Q4 though 2015.Q4. The two intersections of the ZLB-augmented monetary policy rule (solid red line) with the Fisher relationship (dashed black line) define two long-run endpoints. I refer to these two local equilibria as the "targeted" and "deflation" solutions, respectively. The aim of this paper is to develop a quantitative New Keynesian model that can account for the pattern of inflation and interest rates observed in Figure 1 since 1988.

As is well known, the New Keynesian deflation equilibrium is locally indeterminate. I therefore consider a minimum state variable (MSV) solution that rules out sunspot variables and extra lags of fundamental state variables. Model variables in the deflation equilibrium have distributions with lower means and higher variances than those in the targeted equilibrium. But the significant overlap in the various distributions creates a dilemma for an agent

\footnotetext{
${ }^{1}$ I use the terminology "long-run endpoints" rather than "steady states" because the model developed here allows for permanent shifts in the long-run natural real rate of interest ( $r$-star) which, in turn, can shift the long-run values of some macroeconomic variables.
} 
who seeks to determine the degree to which a string of recent data observations are drawn from one local equilibrium or the other.

The model incorporates an exogenous shock to the agent's discount factor that gives rise to movements in the short-run natural real rate of interest. The long-run endpoint of the natural rate process (called $r$-star) is allowed to shift over time in a manner that approximates the $r$-star series estimated by Laubach and Williams (2016).

The representative agent in the model contemplates the possibility of an occasionally binding ZLB that is driven by switching between the two local equilibria. This view turns out to be true in the simulations, thus validating the agent's beliefs. The agent constructs forecasts using a form of model averaging, where the time-varying forecast rule weights are determined by recent performance, as measured by the root mean squared forecast errors for the output gap and inflation (the two variables that the agent must forecast). Sustained intervals when the short-run natural rate of interest remains below the Kalman filter estimate of $r$-star (implying a negative natural rate gap) can induce the agent to place a substantially higher weight on the deflation forecast rules, causing the deflation equilibrium to occasionally become fully realized. These episodes are accompanied by highly negative output gaps, a binding ZLB constraint, and low or negative inflation. But even outside of such episodes, the agent may continue to assign a nontrivial weight to the deflation equilibrium, causing the central bank to persistently undershoot its inflation target.

I solve for the time series of stochastic shocks and endogenous forecast weights that allow the switching model to exactly replicate the observed time paths of the CBO output gap, quarterly PCE inflation, and the federal funds rate since 1988. The data since the start of the ZLB episode in 2008.Q4 are best described as a time-varying mixture of the two local equilibria. The model-implied cost push shock turns positive from 2009.Q2 through 2013.Q1, thus helping to solve the "missing disinflation puzzle" (Coibion and Gorodnichenko 2015). The model-implied weight on the targeted forecast rules undergoes a sustained decline starting in 2008.Q4. Even at the end of the data sample in 2017.Q4, the weight on the targeted forecast rules is only 0.68, thus helping the switching model to account for the persistent undershooting of the Fed's inflation target from 2012 through 2017. In this way, 
the switching model provides a potential explanation for the "missing inflation puzzle" in recent years (Jørgensen and Lansing 2019).

The path of expected inflation in the switching model starts to decline after 2008.Q4 and remains below the Fed's $2 \%$ inflation target through the end of the data sample. This pattern is very similar to the 1-year expected inflation rate derived from inflation swap contracts (Haubrich, Pennacchi, and Ritchken 2012). It is also strongly correlated with the 3-month expected inflation rate implied by the Aruoba Term Structure of Inflation Expectations (ATSIX) framework (Arouba 2019). In a counterfactual exercise that employs the same time series of exogenous shocks, I show that introducing a direct response to the natural rate gap in the monetary policy rule helps to reduce downside fluctuations in the output gap and inflation, thereby increasing the end-of-sample weight assigned to the targeted equilibrium forecast rules.

The results in this paper are closely related to recent work by Aruoba and Schorfheide (2016) and Aruoba, Cuba-Borda, and Schorfheide (2018). These authors construct models in which the economy can switch back and forth between a targeted-inflation regime and a deflation regime, depending on the realization of an exogenous sunspot variable. The two regimes are analogous to the two local equilibria considered here. They employ various model specifications to infer whether interest rate and inflation observations in the data are more likely to have been generated by one regime or the other. Aruoba, Cuba-Borda, and Schorfheide (2018) conclude (p. 116) that: "the U.S. remained in the targeted-inflation regime during its ZLB episode, with the possible exception of the early part of 2009 where evidence is ambiguous."

An important premise underlying the results of Aruoba, Cuba-Borda, and Schorfheide (2018) is that the observed data must come from one regime or the other. But given the data, they compute the time-varying probability that the data was generated by one regime or the other. In contrast, the switching model developed here generates data that is actually a time-varying mixture of the model's two local equilibria. This is due to the time-varying forecast weights assigned by the representative agent in the model. The forecast weights, in turn, influence the model-generated data. So, the deflation equilibrium can influence the model-generated data even if it is never fully realized. Another important difference is that 
the probability of transitioning between the two local equilibria is endogenous here and can therefore be influenced by a change in the monetary policy rule or other model parameters.

The switching model shares some similarities with the work of Sargent (1999) in which the economy can endogenously transition between states of high versus low inflation, depending on policymakers' perceptions about the slope of the long-run Phillips curve. Here, the endogenous switching depends on the representative agent's perceptions about the best forecast weights.

Another related paper is one by Dordal-i-Carrera, et al. (2016). These authors develop a New Keynesian model with volatile and persistent "risk shocks" (i.e., shocks that drive a wedge between the nominal policy rate and the short-term bond rate) to account for infrequent but long-lived ZLB episodes. A risk shock in their model is isomorphic to a short-run natural rate shock here. Large adverse risk shocks are themselves infrequent and long-lived. Unlike here, their analysis does not consider model solutions near the deflation equilibrium, but rather focuses on scenarios in which fundamental shocks are large enough to push the targeted equilibrium to a point where the ZLB becomes binding. ${ }^{2}$ In contrast, the model developed here accounts for infrequent but long-lived ZLB episodes via endogenous switching between two local equilibria, i.e., the shock process itself is not the sole driving force for the infrequent and long-lived ZLB episodes.

As part of the quantitative analysis, I examine how raising the central bank's inflation target can influence the ZLB binding frequency and the volatility of macro variables in the switching model. I find that even with an inflation target of $4 \%$, the ZLB binding frequency remains elevated at around $8 \%$ and the average duration of a ZLB episode is 12.4 quarters. Once the deflation equilibrium is taken into account, raising the inflation target appears to be a less effective solution for avoiding long-lived ZLB episodes.

The New Keynesian deflation equilibrium is often ignored in the literature because it is not locally stable under typical least-squares learning algorithms. However, Mertens and Ravn (2014) demonstrate that the deflation equilibrium remains quantitatively important even in the presence of learning. A somewhat different conclusion is reached by Christiano, Eichenbaum, and Johannsen (2018). Arifovic, Schmitt-Grohé, and Uribe (2018) demonstrate

\footnotetext{
${ }^{2}$ This is also the methodology pursued by Reifschneider and Williams (2000), Schmitt-Grohé and Uribe (2010), Chung, et al. (2012), Coibion, Gorodnichenko, and Wieland (2012), and Kiley and Roberts (2017).
} 
that the deflation equilibria can be locally stable under a form of social learning. Armenter (2018) considers an extension of Benhabib, Schmitt-Grohé and Uribe (2001a,b) in which monetary policy is governed not by a Taylor-type rule, but rather by the optimal interest rate rule under discretion that minimizes the central bank's loss function. He shows that it may not be possible to achieve the targeted equilibrium if agents' initial inflation expectations are below the central bank's inflation target.

\section{Model}

The framework for the analysis is a three equation New Keynesian model, augmented by a zero lower bound constraint on the nominal policy interest rate. The log-linear version of the standard New Keynesian model is taken to represent a set of global equilibrium conditions, with the only nonlinearity coming from the ZLB. The setup is a reduced form version of a fully-specified nonlinear New Keynesian DSGE model, but has the advantage of delivering transparency of the model's dynamics. ${ }^{3}$

Private-sector behavior is governed by the following global equilibrium conditions:

$$
\begin{aligned}
y_{t} & =\widehat{E}_{t} y_{t+1}-\alpha\left[i_{t}-\widehat{E}_{t} \pi_{t+1}-r_{t}\right]+\nu_{t}, \\
\pi_{t} & =\beta \widehat{E}_{t} \pi_{t+1}+\kappa y_{t}+u_{t},
\end{aligned}
$$

where equation (1) is the representative agent's consumption Euler equation and equation (2) is the Phillips curve that is derived from the representative firm's optimal pricing decision. The variable $y_{t}$ is the output gap (the log deviation of real output from potential output), $\pi_{t}$ is the quarterly inflation rate (log difference of the price level), $i_{t}$ is the nominal policy interest rate, and $r_{t}$ is the short-run natural real rate of interest. ${ }^{4}$ As explained further below, the agent's subjective expectations operator $\widehat{E}_{t}$ will approximate a rational expectations operator when solving for the two sets of linear forecast rules associated with each of the two local equilibria. None of the results in the paper are sensitive to the introduction of a discount

\footnotetext{
${ }^{3}$ Armenter (2018) adopts a similar approach in computing the optimal monetary policy under discretion in the presence of two steady states.

${ }^{4}$ Describing $r_{t}$ as the short-run natural rate is consistent with terminologies employed by Barsky, Justiniano, and Melosi (2014), Cúrdia (2015), and Del Negro, et al. (2017).
} 
factor applied to the term $\widehat{E}_{t} y_{t+1}$ in equation (1), along the lines of McKay, Nakamura, and Steinsson (2017).

Fluctuations in $r_{t}$ can be interpreted as arising from changes in the agent's rate of time preference or changes in the expected growth rate of potential output. ${ }^{5}$ As is common in the literature, $r_{t}$ is considered observable by all agents. The time series process for $r_{t}$ is given by

$$
\begin{array}{lll}
r_{t}=\rho_{r} r_{t-1}+\left(1-\rho_{r}\right) r_{t}^{*}+\varepsilon_{t}, & & \varepsilon_{t} \sim N\left(0, \sigma_{\varepsilon}^{2}\right), \\
r_{t}^{*}=r_{t-1}^{*}+\eta_{t}, & \eta_{t} \sim N\left(0, \sigma_{\eta}^{2}\right),
\end{array}
$$

where $\left|\rho_{r}\right|<1$. Equations (3) and (4) summarize a "shifting endpoint" time series process since the long-run natural rate of interest $r_{t}^{*}$ can vary over time due to the permanent shock $\eta_{t}$. I will refer to the unobservable $r_{t}^{*}$ as " $r$-star." The empirical strategies of Laubach and Williams (2016), Lubik and Matthes (2015), and Kiley (2019) all treat $r$-star as a long-run concept. In any given period, the short-run natural rate $r_{t}$ can deviate from $r_{t}^{*}$ as influenced by the history of a temporary shock, represented by $\varepsilon_{t}$. Kozicki and Tinsely (2012) employ this type of process to describe U.S. inflation. When $\rho_{r}=0$, we recover the random walk plus noise process employed by Stock and Watson (2007) to describe U.S. inflation. ${ }^{6}$

The "natural rate gap" is defined as $r_{t}-E_{t} r_{t}^{*}$, where $E_{t} r_{t}^{*}$ represents the Kalman filter estimate of $r$-star. The distinction between the short-run and long-run natural rates of interest is a concept that has been emphasized frequently by Fed policymakers in speeches (Yellen 2015, Dudley 2015, and Fischer 2016). The agent's rational forecast for the natural rate gap at any horizon $h \geq 1$ is given by

$$
E_{t}\left(r_{t+h}-r_{t+h}^{*}\right)=\left(\rho_{r}\right)^{h}\left(r_{t}-E_{t} r_{t}^{*}\right)
$$

which implies that the gap is expected to shrink to zero as the forecast horizon $h$ increases.

\footnotetext{
${ }^{5}$ Specifically, we have $r_{t} \equiv-\log \left[\beta \exp \left(\zeta_{t}\right)\right]+\gamma E_{t} \Delta \bar{y}_{t+1}$, where $\zeta_{t}$ is a shock to the agent's time discount factor $\beta, \bar{y}_{t}$ is the logarithm of real potential output, and $\gamma=\alpha^{-1}$ is the coefficient of relative risk aversion. For the derivation, see Hamilton, et al. (2016) or Gust, Johannsen, and Lopez-Salido (2017).

${ }^{6}$ But unlike here, Stock and Watson (2007) allow for stochastic volatility in the permanent and temporary shocks.
} 
In Supplementary Appendix A, I show that the Kalman filter expression for $E_{t} r_{t}^{*}$ is

$$
\begin{aligned}
& E_{t} r_{t}^{*}=\lambda\left[\frac{r_{t}-\rho_{r} r_{t-1}}{1-\rho_{r}}\right]+(1-\lambda) E_{t-1} r_{t-1}^{*}, \\
& \lambda=\frac{-\left(1-\rho_{r}\right)^{2} \phi+\left(1-\rho_{r}\right) \sqrt{\left(1-\rho_{r}\right)^{2} \phi^{2}+4 \phi}}{2},
\end{aligned}
$$

where $\lambda$ is the Kalman gain parameter and $\phi \equiv \sigma_{\eta}^{2} / \sigma_{\varepsilon}^{2}$. For the quantitative analysis, the values of $\rho_{r}$ and $\lambda$ are chosen so that the time path of $E_{t} r_{t}^{*}$ from equation (6) approximates the one-sided $r$-star series estimated by Laubach and Williams (2016, updated) for the sample period 1988.Q1 to 2017.Q4. Their estimation strategy assumes that $r$-star exhibits a unit root, consistent with equation (4). Equations (3) and (6) imply that $r_{t}-E_{t} r_{t}^{*}$ is stationary.

The variable $\nu_{t}$ represents a demand shock that is distinct from fluctuations in $r_{t}$. Along the lines of Bomfim (2001) and Lorenzoni (2009), the presence of $\nu_{t}$ in equation (1) can be motivated by the existence of measurement error or noisy signals about macroeconomic variables. Alternatively, $\nu_{t}$ can be viewed as capturing fluctuations in the sensitivity of the output gap to changes in $i_{t}$. The variable $u_{t}$ in equation (2) represents a cost-push shock that can be motivated by a time-varying elasticity of substitution among goods or a time-varying tax rate on labor income. The shocks evolve according to following stationary laws of motion:

$$
\begin{array}{ll}
\nu_{t}=\rho_{\nu} \nu_{t-1}+\epsilon_{\nu, t}, & \epsilon_{\nu, t} \sim N\left[0, \sigma_{\nu}^{2}\left(1-\rho_{\nu}^{2}\right)\right], \\
u_{t}=\rho_{u} u_{t-1}+\epsilon_{u, t}, & \epsilon_{u, t} \sim N\left[0, \sigma_{u}^{2}\left(1-\rho_{u}^{2}\right)\right],
\end{array}
$$

where $\left|\rho_{\nu}\right|<1$ and $\left|\rho_{u}\right|<1$.

The central bank's monetary policy rule is given by

$$
\begin{aligned}
i_{t}^{*} & =\rho i_{t-1}^{*}+(1-\rho)\left[E_{t} r_{t}^{*}+\pi^{*}+g_{\pi}\left(\bar{\pi}_{t}-\pi^{*}\right)+g_{y}\left(y_{t}-y^{*}\right)+g_{r}\left(r_{t}-E_{t} r_{t}^{*}\right)\right] \\
\bar{\pi}_{t} & =\omega \pi_{t}+(1-\omega) \bar{\pi}_{t-1}, \\
i_{t} & =0.5 i_{t}^{*}+0.5 \sqrt{\left(i_{t}^{*}\right)^{2}}
\end{aligned}
$$

where $i_{t}^{*}$ is the desired nominal interest rate that responds to deviations of recent inflation $\bar{\pi}_{t}$ from the central bank's target rate $\pi^{*}$ and to deviations of the output gap from its targeted endpoint $y^{*}$. The policy rule also allows for a direct response to the natural rate gap, along 
the lines of the policy rules considered by Cúrdia, et al. (2015) and Gust, Johannsen, and Lopez-Salido (2017).

The quantity $E_{t} r_{t}^{*}+\pi^{*}$ represents the targeted endpoint of $i_{t}^{*}$. Including $E_{t} r_{t}^{*}$ in the policy rule implies that monetary policymakers continually update their estimate of the unobservable $r$-star. Support for this idea can be found in the Federal Open Market Committee's Summary of Economic Projections (SEP). Meeting participants provide their views on the projected paths of macroeconomic variables over the next three calendar years and in the longer run. The median SEP projection for $r$-star can be inferred by subtracting the median longerrun projection for inflation from the median longer-run projection for the nominal federal funds rate. The $r$-star projection computed in this way has ratcheted down over time, as documented by Lansing (2016).

Equation (11) defines recent inflation $\bar{\pi}_{t}$ as an exponentially-weighted moving average of current and past quarterly inflation rates so as to approximate the compound average inflation rate over the past 4 quarters - a typical central bank target variable. ${ }^{7}$ Equation (12) is a computationally convenient way of imposing the ZLB constraint in model simulations where the four endogenous variables $y_{t}, \pi_{t}, i_{t}^{*}$ and $i_{t}$ are all determined simultaneously by solving a nonlinear system of four equations each period. ${ }^{8}$ The parameter $\rho \in[0,1)$ governs the degree of interest rate smoothing as $i_{t}^{*}$ adjusts partially each period toward the value implied by the terms in square brackets. Similar to the policy rule employed by Dordal-i-Carrera, et al. (2016), equation (10) keeps track of past negative values of $i_{t}^{*}$, thereby exhibiting a form of commitment to keep interest rates "lower for longer" whenever the ZLB becomes binding.

\subsection{Long-run endpoints}

The Fisher relationship is embedded in the non-stochastic version of equation (1). ${ }^{9}$ Consequently, when $g_{\pi}>1$, the model has two long-run endpoints (steady states) as shown originally

\footnotetext{
${ }^{7}$ Specifically, the value of $\omega$ is set to achieve $\bar{\pi}_{t} \simeq\left[\Pi_{j=0}^{3}\left(1+\pi_{t-j}\right)\right]^{0.25}-1$

${ }^{8}$ The computation procedure is described in Section 2.3 and in Supplementary Appendices B and C. Equation (12) is readily generalized to allow for negative nominal interest rates by imposing the constraint $i_{t}=E L B+0.5\left(i_{t}^{*}-E L B\right)+0.5 \sqrt{\left(i_{t}^{*}-E L B\right)^{2}}$, where $E L B \leq 0$ is the "effective lower bound" on the nominal policy interest rate.

${ }^{9}$ Uribe (2018) examines the strength of Fisherian effects in both empirical and optimizing models. He finds a that a permanent increase in the nominal interest rate causes inflation to increase immediately.
} 
by Benhabib, Schmitt-Grohé, and Uribe (2001a,b). The novelty here is that the long-run endpoints of some macroeconomic variables can shift due to shifts in $r_{t}^{*}$. Straightforward computations using the model equations yield the following long-run endpoints for the targeted equilibrium: $\pi_{t}=\pi^{*}, y_{t}=y^{*} \equiv \pi^{*}(1-\beta) / \kappa$, and $i_{t}^{*}=i_{t}=r_{t}^{*}+\pi^{*}$. For the deflation equilibrium, the long-run endpoints are $\pi_{t}=-r_{t}^{*}, y_{t}=-r_{t}^{*}(1-\beta) / \kappa, i_{t}^{*}=\left(r_{t}^{*}+\pi^{*}\right)\left[1-g_{\pi}-g_{y}(1-\beta) / \kappa\right]$, and $i_{t}=0$.

In the model simulations, I impose bounds on fluctuations in $r_{t}^{*}$ that are based on the range of $r$-star estimates observed in the data since 1988.

\subsection{Local linear forecast rules}

Given the linearity of the model aside from the ZLB, it is straightforward to derive the agent's rational decision rules for $y_{t}$ and $\pi_{t}$ in the vicinity of the long-run endpoints associated with each of the two local equilibria. For the targeted equilibrium, the local decision rules are unique linear functions of the six state variables $r_{t}, E_{t} r_{t}^{*}, \bar{\pi}_{t-1}, i_{t-1}^{*}, \nu_{t}$, and $u_{t}$. For the deflation equilibrium, I solve for the minimum state variable (MSV) solution which abstracts from extraneous sunspot variables and extra lags of fundamental state variables. ${ }^{10}$ For both equilibria, the current estimate of $r$-star, given by $E_{t} r_{t}^{*}$, is a state variable. For the targeted equilibrium, $E_{t} r_{t}^{*}$ is a state variable because its appears in the monetary policy rule (10). For the deflation equilibrium, $E_{t} r_{t}^{*}$ is a state variable because it pins down the agent's current estimates of the long-run endpoints for $\pi_{t}$ and $y_{t}$.

The decision rule coefficients that multiply the natural rate gap $r_{t}-E_{t} r_{t}^{*}$ in the deflation equilibrium are larger in magnitude than those in the targeted equilibrium (see Supplementary Appendices B and C). Consequently, the deflation equilibrium exhibits more volatility and undergoes a more severe recession in response to an adverse shock sequence that causes the natural rate gap to become persistently negative. The higher volatility in the deflation equilibrium is due to the binding ZLB which prevents the central bank from taking action to mitigate the consequences of the adverse shock sequence.

Given the local linear decision rules, I construct the agent's local linear forecast rules for

\footnotetext{
${ }^{10}$ For background on MSV solutions, see McCallum (1999).
} 
$y_{t+1}$ and $\pi_{t+1}$ in each of the two equilibria. The local linear forecast rules for the targeted equilibrium are derived under the assumption that $i_{t}^{*}>0$ for all $t$ and hence ignore the possibility that a shock sequence could be large enough to cause the ZLB to become binding. Based on model simulations, the targeted equilibrium experiences a binding ZLB in only $1.08 \%$ of the periods, with an average duration of 5.2 quarters. The local linear forecast rules for the deflation equilibrium are derived under the assumption that $i_{t}^{*} \leq 0$ for all $t$ and hence ignore the possibility that a shock sequence could be large enough to cause the ZLB to become slack. Based on model simulations, the deflation equilibrium experiences a binding ZLB in $79.3 \%$ of the periods, with an average duration of 37.9 quarters. The average duration of a slack ZLB episode in the deflation equilibrium is 9.9 quarters. It is important to recognize, however, that the agent in the switching model (described below) never encounters these statistics because they pertain to environments with no forecast switching.

In the switching model, the agent's subjective forecasts for $y_{t+1}$ and $\pi_{t+1}$ allow for the possibility of an occasionally binding ZLB that is driven by switching between two local equilibria. The two sets of linear forecast rules employed for each of the two local equilibria are valid in the vicinities of their respective long-run endpoints. In simulations of the switching model, the agent's forecast errors for $y_{t+1}$ and $\pi_{t+1}$ are close to white noise. ${ }^{11}$

Aruoba, Cuba-Borda, and Schorfheide (2018) solve for piece-wise Chebyshev polynomial decision rules to account for the occasionally binding nature of the ZLB constraint within each of the two regimes of their model (analogous to the two local equilibria here). They report (p. 104), that the probability of hitting the ZLB in the targeted-inflation regime is "virtually zero" given the pre-crisis distribution of shocks. In the deflation regime, the probability of hitting the ZLB is $89 \%$. These statistics are similar to those obtained here using the local linear forecast rules.

Focusing only on the targeted equilibrium, Richter and Throckmorton (2016) compare a linear model solution in which agents' forecasts do not account for the possibility of hitting the ZLB (but the ZLB is imposed in simulations, as is done here) to a nonlinear model solution in which agents' forecasts do account for this possibility. They report that the posterior

\footnotetext{
${ }^{11}$ Properties of the agent's forecast errors in each of the two local equilibria and in the switching model are provided in Supplementary Appendix E.
} 
distributions and marginal likelihoods of the two models are quite similar. But the nonlinear model predicts higher output volatility and more-negative skewness in output and inflation during the ZLB episode.

\subsection{Endogenous forecast switching}

I now consider an agent who contemplates the possibility of an occasionally binding ZLB that is driven by switching between the two local equilibria. The agent in the switching model can be viewed as an econometrician trying to identify the best forecast rule for the environment. The agent constructs forecasts using a form of model averaging - a technique that is often employed to improve forecast performance in environments where the true data generating process is unknown (Timmerman 2006). Along the lines of Bullard (2010), the agent is aware of the two local equilibria and is concerned about the possibility of getting stuck in a deflation trap. The agent's subjective forecasts in the switching model are given by

$$
\begin{aligned}
& \widehat{E}_{t} y_{t+1}=\mu_{t} \widehat{E}_{t}^{\operatorname{targ}} y_{t+1}+\left(1-\mu_{t}\right) \widehat{E}_{t}^{\text {defl }} y_{t+1}, \\
& \widehat{E}_{t} \pi_{t+1}=\mu_{t} \widehat{E}_{t}^{\operatorname{targ}} \pi_{t+1}+\left(1-\mu_{t}\right) \widehat{E}_{t}^{\text {defl }} \pi_{t+1},
\end{aligned}
$$

where $\widehat{E}_{t}^{\mathrm{targ}}$ and $\widehat{E}_{t}^{\mathrm{defl}}$ represent the predictions implied by the linear forecast rules associated with each of the two local equilibria. The variable $\mu_{t}$ is the weight assigned to the forecasts implied by the targeted equilibrium and $1-\mu_{t}$ is the weight assigned to the forecasts implied by the deflation equilibrium. The value of $\mu_{t}$ is chosen to optimize forecast performance over a window of recent data. Specifically, $\mu_{t}$ is the value that minimizes:

$$
\begin{aligned}
& R M S F E_{t-1}=\sum_{j=1}^{T_{w}}\left\{\frac{1}{T_{w}}\left[y_{t-j}-\mu_{t} \widehat{E}_{t-j-1}^{\mathrm{targ}} y_{t-j}-\left(1-\mu_{t}\right) \widehat{E}_{t-j-1}^{\mathrm{defl}} y_{t-j}\right]^{2}\right. \\
&\left.+\frac{1}{T_{w}}\left[\pi_{t-j}-\mu_{t} \widehat{E}_{t-j-1}^{\mathrm{targ}} \pi_{t-j}-\left(1-\mu_{t}\right) \widehat{E}_{t-j-1}^{\mathrm{defl}} \pi_{t-j}\right]^{2}\right\}^{0.5},
\end{aligned}
$$

which shows that $\mu_{t}$ is computed using data dated $t-1$ or earlier. In the simulations, I impose the restriction $0 \leq \mu_{t} \leq 1$.

Given the realizations of the exogenous variables $r_{t}, \nu_{t}$, and $u_{t}$, together with $E_{t} r_{t}^{*}$ from equation (6), the representative agent computes the conditional forecasts from equations (13) and (14) with $\mu_{t}$ given by the value that minimizes equation (15). Given these forecasts, the 
realizations of the four endogenous variables $y_{t}, \pi_{t}, i_{t}^{*}$ and $i_{t}$ are determined simultaneously each period by solving the nonlinear system of four equations given by (1), (2), (10), and (12).

\section{Parameter values}

Table 1 shows the baseline parameter values used in the quantitative analysis. The value $\alpha=0.15$ for the interest rate sensitivity coefficient in equation (1) implies a coefficient of relative risk aversion of $1 / \alpha \simeq 6.7$. This value is consistent with the small empirical sensitivity of consumption to changes in the interest rate, as shown originally by Campbell and Mankiw (1989). The values $\beta=0.995$ and $\kappa=0.025$ imply a low rate time preference together with a relatively flat Phillips curve. The parameters that govern the demand shock in equation (8) and the cost push shock in equation (9) are computed from a quantitative exercise (described in Section 4.3) in which I solve for the sequences of $\nu_{t}$ and $u_{t}$ that allow the switching model to exactly replicate the observed time paths of U.S. data since 1988.

The inflation target of $\pi^{*}=0.02$ is based on the Federal Open Market Committee's (FOMC) stated goal of $2 \%$ inflation, as measured by the 4-quarter change in the personal consumption expenditures (PCE) price index. I choose $\omega=0.456$ to minimize the squared deviation between the 4-quarter PCE inflation rate and the exponentially-weighted moving average of quarterly PCE inflation computed from equation (11) for the period 1961.Q1 to 2017.Q4. When $\omega=0.456$, the cumulative weight on the first four terms $\pi_{t}$ through $\pi_{t-3}$ in the moving average is 0.912. In simulations, the mean, standard deviation, and autocorrelation statistics for $\bar{\pi}_{t}$ are nearly identical to those for the 4-quarter inflation rate. The monetary policy rule coefficients $g_{\pi}, g_{y}$ and $\rho$ are based on the Taylor (1999) rule, augmented to allow for a realistic amount of inertia in the desired nominal policy rate. The baseline calibration sets $g_{r}=0$, but I consider a counterfactual exercise with $g_{r}>0$.

For the short-run natural rate $r_{t}$, I use the series estimated by Cúrdia, et al. (2015). ${ }^{12}$ Similar results are obtained using the short-run natural rate series estimated by Del Negro, et al. (2017). The top left panel of Figure 3 plots the $r_{t}$ series from 1988.Q1 to 2017.Q4

\footnotetext{
${ }^{12}$ Updated data are from www.frbsf.org/economic-research/economists/vasco-curdia/.
} 
together with the Laubach-Williams one-sided estimate of $r$-star. ${ }^{13}$ When $\rho_{r}=0.875$ and $\lambda=0.015$, the Kalman filter expression for $E_{t} r_{t}^{*}$ from equation (6) closely approximates the path of the Laubach-Williams $r$-star series. Similar results are obtained if $\rho_{r}$ and $\lambda$ are chosen to approximate an alternative $r$-star series estimated by Lubik and Matthes (2015). Given the considerable uncertainty surrounding estimates of $r$-star, any observed differences between the estimated series are not statistically significant.

Given the values of $\rho_{r}$ and $\lambda$, I solve for the value $\phi \equiv \sigma_{\eta}^{2} / \sigma_{\varepsilon}^{2}=0.0146$ to satisfy the Kalman gain formula (7). Given $\phi$, I solve for the value of $\sigma_{\varepsilon}$ that allows the model-predicted standard deviation of $\Delta r_{t}$ to match the corresponding value in the data for the period 1988.Q1 to 2017.Q4. Finally, given $\phi$ and $\sigma_{\varepsilon}$, we have $\sigma_{\eta}=\sigma_{\varepsilon} \sqrt{\phi}$.

The window length for computing the agent's forecast fitness measure from equation (15) is set to $T_{w}=8$ quarters. In simulations, this value produces a ZLB binding frequency of around $16 \%$-reasonably close to the frequency observed in U.S. data since 1988. I also examine the sensitivity of the results to a lower value of $T_{w}$. Lower values of $T_{w}$ serve to increase the ZLB binding frequency.

For the baseline simulation, I impose the bounds $0.0006 \leq r_{t}^{*} \leq 0.0422$, which corresponds to the range of values for the model-implied $E_{t} r_{t}^{*}$ series. ${ }^{14}$ Based on a life cycle model calibrated to the U.S. economy in 2015, Eggertsson, Mehrotra, and Robbins (2019) compute a steady-state natural rate of $-1.5 \%$. In a representative agent model, $r$-star influences the mean risk free rate of return. The mean risk free rate can be negative if the product of the coefficient of relative risk aversion and the variance of consumption growth are sufficiently high, implying a very strong precautionary saving motive. ${ }^{15}$ Using a small macroeconomic model together with global data, Kiley (2019) estimates an $r$-star value of $-1 \%$ for the U.S. economy in 2019. To allow for more negative values of $r$-star, I consider an alternative simulation that

\footnotetext{
${ }^{13}$ The $r$-star series is from https://www.newyorkfed.org/research/policy/rstar and is based on data available on April 1, 2019.

${ }^{14}$ Alternatively, one could model $r_{t}^{*}$ as a "bounded random walk" along the lines described by Nicolau (2002). But this approach involves additional parameters and presumes that the agent has prior knowledge of the upper and lower bounds on $r_{t}^{*}$.

${ }^{15}$ Assuming iid consumption growth and power utility, the mean risk free rate is given by $E\left[\log \left(R_{t+1}^{f}\right)\right]=$ $-\log (\beta)+\gamma \bar{x}-\gamma^{2} \sigma_{x}^{2} / 2$, where $\beta$ is the discount factor, $\gamma$ is the coefficient of relative risk aversion, $\bar{x}$ is the mean growth rate of real per capita consumption and $\sigma_{x}^{2}$ is the corresponding variance. For details of the derivation, see Lansing and LeRoy (2014).
} 
imposes the bounds $-0.02 \leq r_{t}^{*} \leq 0.02$.

\section{Quantitative analysis}

\subsection{Results for a simplified model}

The model is self-referential, meaning that the agent's subjective forecasts from equations (13) and (14) tend to strongly influence the subsequent trajectories of $y_{t}$ and $\pi_{t}$. If the representative agent starts putting some weight on the deflation equilibrium forecast rules, then the model economy will generate data that tends to confirm the agent's belief that putting some weight on the deflation equilibrium forecast rules helps to improve forecast performance. This idea can be illustrated using a simplified version of the model that imposes $\rho=0, \omega=1$, $\sigma_{\nu}=0, \sigma_{u}=0$, and $\sigma_{\eta}=0$. Under these settings, $i_{t-1}^{*}$ and $\bar{\pi}_{t-1}$ drop out as state variables, the shocks $\nu_{t}$ and $u_{t}$ are zero for all $t$, and $r^{*}$ is constant. I set $r^{*}=0.0079$, corresponding to the mean of the $r_{t}$ series estimated by Cúrdia, et al. (2015). Other parameter values are identical to those shown in Table 1. Closed form expressions for the decision rules associated with each of the two local equilibria are provided in Supplementary Appendix D.

To understand the self-confirming nature of the agent's forecasts, consider a situation when $r_{t} \simeq r^{*}>0$ for several periods in a row. In this case, the agent's weighted-average forecast rule for inflation from equation (14) would be given by $\widehat{E}_{t} \pi_{t+1} \simeq \mu_{t} \pi^{*}+\left(1-\mu_{t}\right)\left(-r^{*}\right)$. An

arbitrary reduction in $\mu_{t}$ would serve to decrease $\widehat{E}_{t} \pi_{t+1}$, thereby putting downward pressure on $\pi_{t}$ via the Phillips curve equation (2). When $\pi_{t}$ goes down, the deflation equilibrium forecast of $-r^{*}$ from the previous period will be viewed as having improved its performance relative to the targeted equilibrium forecast of $\pi^{*}$. This result, in turn, motivates the agent to reduce $\mu_{t+1}$ in the subsequent period. These various movements are all reversed for an arbitrary increase in $\mu_{t}$. The presence of stochastic shocks simply adds noise and sampling variation to these basic self-confirming dynamics.

If the agent could somehow commit to employing the forecast weight $\mu_{t}=1$ for all $t$, then $y_{t}$ and $\pi_{t}$ would always fluctuate around the targeted endpoints. But if the agent seeks to improve forecast performance by employing other values such that $0 \leq \mu_{t}<1$, then sustained departures away from the targeted endpoints become possible. Interestingly, it is agent's 
subjective belief in the possibility of the deflation equilibrium that allows it to occasionally become a reality.

Later in Section 4.3, I use the full switching model to extract the time-varying forecast weight $\mu_{t}$ implied by U.S. data from 1988 onward. Here I use the simplified model to validate the methodology. Specifically, the simplified model is used to generate simulated data for $y_{t}$ and $\pi_{t}$ using an exogenous weight $\mu$ on the targeted forecast rules, where $\mu$ undergoes a series of infrequent shifts. The switching model's algorithm for determining $\mu_{t}$ is to minimize the $R M S F E$ statistic from equation (15) with $T_{w}=8$. Applying this algorithm to the model's simulated data for $y_{t}$ and $\pi_{t}$ produces a time series for $\mu_{t}$ that optimizes forecast performance over the past 8 quarters. The results of the validation exercise are plotted in Figure 2. The switching model's algorithm for determining $\mu_{t}$ (thin red line) successfully tracks the actual value of $\mu$ (thick blue line) that is being used to generate the data.

\section{$4.2 \quad$ U.S. data around the ZLB episode}

As a prelude to the U.S. data replication exercise involving the full switching model, Figure 3 plots the relevant data from 1988.Q1 to 2017.Q4. The top left panel shows that the short-run natural rate of interest $r_{t}$ remains below the model-implied value of $E_{t} r_{t}^{*}$ from 2007.Q4 (the start of the Great Recession) onward, implying a negative natural rate gap. The bottom left panel shows that the nominal federal funds rate $i_{t}$ was approximately zero from 2008.Q4 through 2015.Q4. Assuming $i_{t}^{*}=i_{t}$ in 2008.Q4, the desired federal funds rate from 2009.Q1 through 2015.Q4 is computed using the calibrated policy rule (10) with $E_{t} r_{t}^{*}$ given by modelimplied value from equation (6), $\bar{\pi}_{t}$ given by the 4 -quarter PCE inflation rate, and $y_{t}$ given by the CBO output gap. From 2016.Q1 onward, I assume $i_{t}^{*}=i_{t}$.

The top right panel of Figure 3 shows that the 4-quarter PCE inflation rate was negative for three consecutive quarters in 2009 and remains mostly below the Fed's $2 \%$ inflation target from 2012.Q2 onward. The bottom right panel shows that the Great Recession was very severe, pushing the CBO output gap down to $-6.1 \%$ at the business cycle trough in 2009.Q2. This was the most severe economic contraction since 1947 as measured by the peak-to-trough decline in real GDP. The output gap is negative through 2017.Q4, more than eight years after 
the Great Recession ended. The various endpoints plotted in Figure 3 are computed using the expressions in Section 2.1, with $r_{t}^{*}$ set equal to the model-implied value of $E_{t} r_{t}^{*}$. As $E_{t} r_{t}^{*}$ approaches zero or becomes negative, the so-called "deflation" equilibrium is characterized by zero or low positive inflation, allowing this equilibrium to provide a better fit of recent U.S. inflation data.

\subsection{Replicating U.S. data with the switching model}

Given the U.S. data counterparts for the model variables, I use the calibrated switching model to solve for the time series of the two persistent shocks $\nu_{t}$ and $u_{t}$ and the endogenous forecast weight $\mu_{t}$ that are needed to exactly replicate the data from 1988.Q2 onward. ${ }^{16}$ For this computation, the agent's subjective forecasts $\widehat{E}_{t} y_{t+1}$ and $\widehat{E}_{t} \pi_{t+1}$ are constructed as the weighted averages shown in equations (13) and (14), but with U.S. data inserted for the state variables that appear in the two sets of local linear forecast rules. The initial conditions at 1988.Q1 are the U.S. data values of the state variables together with $\nu_{t}=u_{t}=0$. The natural rate gap $r_{t}-E_{t} r_{t}^{*}$ is given by the difference between the short-run natural rate from Cúrdia, et al. (2015) and the model-implied value of $E_{t} r_{t}^{*}$ from equation (6). The variable $y_{t}$ is the CBO output gap, $\pi_{t}$ is quarterly PCE inflation, and $\bar{\pi}_{t} \simeq \pi_{4, t}$ is 4-quarter PCE inflation. The variable $i_{t}$ is the nominal federal funds rate. I set $i_{t}^{*}=i_{t}$ except during the interval from 2009.Q1 through 2015.Q4. During this interval, $i_{t}^{*}$ is given by the value implied by the calibrated policy rule (10), as plotted earlier in Figure 3. Starting in 1990.Q2, the endogenous forecast weight $\mu_{t}$ is computed each period so as to minimize the RMSFE statistic from equation (15) with $T_{w}=8$. Before 1990.Q2, I impose $\mu_{t}=1$. The shock persistence parameters $\rho_{\nu}$ and $\rho_{u}$ influence the values of the coefficients in the local linear forecast rules. I start with initial guesses for $\rho_{\nu}$ and $\rho_{u}$ and then repeat the replication exercise until approximate convergence. The resulting standard deviations of $\nu_{t}$ and $u_{t}$ are 0.003 and 0.010 , respectively, with $\rho_{\nu}=0.85$ and $\rho_{u}=0.32$.

The results of the data replication exercise are plotted in Figure 4. The top left panel plots the model-implied shocks $\nu_{t}$ and $u_{t}$. Both shocks go from positive to negative at the start of

\footnotetext{
${ }^{16}$ For similar reverse-engineering exercises in the context of different economic settings, see Lansing and Markiewicz (2018), Gelain, Lansing, and Natvik (2018), and Lansing (2019).
} 
the ZLB episode in 2008.Q4. These adverse shocks allow the model to exactly replicate the sharp drops in the CBO output gap and PCE inflation shown earlier in Figure 3. The cost push shock $u_{t}$ turns positive from 2009.Q2 through 2013.Q1, thus helping to solve the "missing disinflation puzzle."

The top right panel of Figure 4 compares the RMSFE of the deflation forecast rules to the RMSFE of the targeted forecast rules. The performance gap between the two sets of forecast rules initially narrows with the onset of the ZLB episode in 2008.Q4. This result leads to an initial sharp drop in the weight $\mu_{t}$ assigned to targeted forecast rules (bottom right panel). The performance gap narrows even further after 2012.Q2 when the Fed consistently undershoots its $2 \%$ inflation target, inducing a further decline in $\mu_{t}$. At the end of the data sample in 2017.Q4, the value of $\mu_{t}$ is 0.68 and the RMSFE of the switching model forecast rules lies below the RMSFE of the targeted forecast rules. Recall that the long-run endpoint for $\pi_{t}$ in the deflation equilibrium is $-r_{t}^{*}$. Since $E_{t} r_{t}^{*}$ is close to zero at the end of the U.S. data sample, putting some weight on the deflation forecast rules helps to account for the observation of below-target inflation in the U.S. data.

The bottom left panel of Figure 4 compares the switching model prediction for expected inflation $\widehat{E}_{t} \pi_{t+1}$ to two U.S. data series that are not explicitly replicated. These are the 1year expected inflation rate derived from inflation swap contracts and the 3 -month expected inflation rate implied by the Aruoba Term Structure of Inflation Expectations (ATSIX) framework. ${ }^{17}$ Expected inflation from the switching model starts to decline after 2008.Q4 and remains below the Fed's $2 \%$ inflation target through the end of the data sample. This pattern is very similar to the expected inflation series from swap contracts. The ATSIX expected inflation series also experiences a sharp drop in 2008.Q4 followed by an eventual recovery to $2 \%$, but the series nevertheless remains below its pre-recession level at the end of the data sample. The correlation coefficients between the model's expected inflation series and the two U.S. data series are 0.81 and 0.63 , respectively.

Of course, one could solve for different sequences of $\nu_{t}$ and $u_{t}$ that would allow the targeted

\footnotetext{
${ }^{17}$ Expected inflation from swap contracts is available from the Federal Reserve Bank of Cleveland. Expected inflation from ATSIX is available from the Federal Reserve Bank of Philadelphia from 1998 onward. The ATSIX data from 1992 through 1997 was kindly provided by Boroğan Aruoba.
} 
equilibrium with $\mu_{t}=1$ for all $t$, or the deflation equilibrium with $\mu_{t}=0$ for all $t$, to similarly replicate the U.S. data. But the RMSFE minimization procedure employed by the agent prefers a time-varying mixture of the two local equilibria with $0<\mu_{t} \leq 1$.

The bottom right panel of Figure 4 also shows the results for an alternative exercise that employs the same sequences for the shocks $\nu_{t}$ and $u_{t}$, but instead sets $r_{t}$ equal to $E_{t} r_{t}^{*}$ in the data so that the natural rate gap is zero for all $t$. The resulting forecast weight $\mu_{t}$ now stays much closer to 1.0. This alternative exercise shows that the persistently negative natural rate gap in the data is an important contributor to the downward drift in the forecast weight $\mu_{t}$.

Can the results of the data replication exercise be reconciled with those of Arouba, CubaBorda, and Schorfheide (2018), henceforth ACS? I believe so. Recall that ACS conclude that "the U.S. remained in the targeted-inflation regime during its ZLB episode, with the possible exception of the early part of 2009 where evidence is ambiguous." ${ }^{18}$ First, according to the ACS model, the economy must be in either the targeted-inflation regime or the deflation regime. In contrast, the data replication exercise tells us that the U.S. data since 2008.Q4 are best described as a time-varying mixture of the two local equilibria. But ACS do not allow for such a mixture. Second, while ACS explicitly consider model uncertainty, a number of their model parameters are fixed during the estimation routine. The most notable of these is $r$-star which is held constant at $0.86 \%$. The uncertainty surrounding point estimates of $r$-star is extremely large. It could easily be the case that true value of $r$-star is significantly lower, or even negative as suggested by Eggertsson, Mehrotra, and Robbins (2019) and Kiley (2019). The model-implied value of $E_{t} r_{t}^{*}$ in Figure 3 is approximately zero in 2017.Q4. If $r$-star is zero or even negative, then the so-called "deflation" equilibrium need not be characterized by actual negative inflation. Putting some weight on this "low inflation" equilibrium would help the model explain a sustained period of below-target inflation.

\footnotetext{
${ }^{18}$ More specifically, they acknowledge (p. 111) that across the six specifications of their model, "there is some uncertainty which vindicates Bullard (2010)'s concern of the possibility of a shift to the deflationary regime."
} 


\subsection{Counterfactual exercise: Policy response to natural rate gap}

As noted above, the persistently negative natural rate gap in the U.S. data is an important contributor to the post-2008 downward drift in the forecast weight $\mu_{t}$. Here I show that allowing for a direct response to $r_{t}-E_{t} r_{t}^{*}$ in the policy rule (10) can achieve better economic outcomes. Along similar lines, Gust, Johannsen, and Lopez-Salido (2017) show that allowing for a direct response to $r_{t}$ in a Taylor-type rule can achieve results that are similar to optimal discretionary policy. Cúrdia, et al. (2015) present evidence suggesting that the Fed may indeed respond directly to $r_{t}$. Responding to the natural rate gap would not represent a major shift in the conduct of monetary policy and is an idea that can be communicated readily to the public. As noted earlier, Fed policymakers have frequently discussed the concept of a natural rate gap in speeches (Yellen 2015, Dudley 2015, and Fischer 2016). Price level targeting, in contrast, would involve significant complications, such as choosing and clearly communicating the reference dates for when the targeted price level trajectory begins or ends (Bernanke 2017).

It can be shown that when $\rho=0$ (no interest rate smoothing), setting $g_{r}=1$ in the targeted equilibrium fully stabilizes both $y_{t}$ and $\pi_{t}$ against fluctuations in $r_{t}-E_{t} r_{t}^{*}$. It turns out that an even stronger response with $g_{r}>1$ can further improve outcomes when $\rho=0.8$, as in the calibration employed here.

Figure 5 shows the results of a counterfactual exercise that employs the same initial conditions and the same sequences for $\nu_{t}, u_{t}, r_{t}$, and $E_{t} r_{t}^{*}$ as in Figure 4 , but now imposes $g_{r}=1.5$ in the monetary policy rule. Relative to the baseline exercise, the counterfactual exercise lengthens the ZLB episode by 7 quarters, but it succeeds in reducing downside fluctuations in the output gap and inflation, thereby increasing the end-of-sample weight $\mu_{t}$ assigned to the targeted forecast rules. In 2017.Q4, the value of $\mu_{t}$ is now 0.80 versus 0.68 in the baseline exercise. As a caveat, the considerable uncertainty surrounding estimates of the natural rate gap could mitigate these improved outcomes.

\subsection{Switching model simulations}

Additional insights can be obtained from stochastic simulations of the switching model. Figure 6 plots the distributions of macro variables in the switching model versus the corresponding 
distributions in the two local equilibria. Each of the three distributions is based on a 300,000 period simulation using the same sequences of exogenous shocks. ${ }^{19}$ Macro variables in the deflation equilibrium have distributions with lower means but higher variances than those in the targeted equilibrium. But the significant overlap in the various distributions creates a dilemma for an agent who seeks to determine the degree to which a string of recent data observations are drawn from one local equilibrium or the other. Variables in the switching model have means that are somewhat lower and variances that are somewhat higher than those in the targeted equilibrium. Consequently, the central bank in the switching model undershoots its inflation target and the volatilities of the output gap and inflation are both higher than those in the targeted equilibrium.

Hills, Nakata, and Schmidt (2019) show that the risk of encountering the ZLB in the future can shift agents' expectations such that the central bank undershoots its inflation target in the present. Something similar is at work here. When the representative agent increases the weight on the deflation equilibrium forecast rules, this can cause realized inflation to undershoot the central bank's target for a sustained interval, even when the ZLB is not binding. The switching model allows for low-frequency swings in the level of inflation that are driven solely by expectational feedback, not by changes in the monetary policy rule. ${ }^{20}$

As mentioned above, the U.S. output gap reached $-6.1 \%$ at the trough of the Great Recession in 2009.Q2. The bottom right panel of Figure 6 shows that the likelihood of such an event in the targeted equilibrium is essentially zero. In contrast, a Great Recession-type episode is rare but plausible in the switching model. Severe recessions can happen in the switching model due to the larger response coefficients on the natural rate gap $r_{t}-E_{t} r_{t}^{*}$ and the demand shock $\nu_{t}$ in the deflation equilibrium decision rule for $y_{t}$. These larger response coefficients (which also appear in the deflation equilibrium forecast rules) have more influence on the switching model as the forecast weight $\mu_{t}$ declines. Lower values of $\mu_{t}$ cause adverse

\footnotetext{
${ }^{19}$ Computational details for the two local equilibria are provided in Supplementary Appendices B and C. The representative agent's local linear forecast rules assume that either the ZLB is never binding (targeted) or always binding (deflation). But in the stochastic simulations, the ZLB can be sometimes binding or sometimes slack, as determined by equation (12).

${ }^{20}$ Lansing (2009) achieves a similar result in a model where the representative agent's forecast rule for quarterly inflation is based on a perceived law of motion that follows a Stock and Watson (2007) type time series process.
} 
realizations of $r_{t}-E_{t} r_{t}^{*}$ or $\nu_{t}$ to be transmitted more forcefully to the output gap.

Some have argued that the deflation equilibrium does not provide a convincing explanation of the sluggish U.S. output recovery following the Great Recession because the steady state level of real activity in the deflation equilibrium is not much below the steady state level of real activity in the targeted equilibrium. However, this argument fails to account for the outof-steady-state behavior of the deflation equilibrium which is highly responsive to a negative natural rate gap. A negative natural rate gap puts strong downward pressure on $y_{t}$ in the deflation equilibrium. The U.S. natural rate gap has remained significantly negative since the Great Recession ended, as can be seen in the top left panel of Figure 3. Consequently, putting some forecast weight on the deflation equilibrium can help to explain the sluggish U.S. output recovery even if the deflation equilibrium is never fully realized in the data.

Table 2 provides a quantitative comparison between the U.S. data and the results of the switching model simulations. ${ }^{21}$ For the most part, the statistics generated by the baseline switching model compare favorably to those in U.S. data since 1988. For example, the switching model predicts a ZLB binding frequency of $15.8 \%$ versus $24.2 \%$ in the data. Going forward, the ZLB binding frequency in U.S. data is likely to decline over time, assuming that the previous 7-year ZLB episode was a rare event. Notice, however, that the mean 4-quarter inflation rate in the switching model is only $0.92 \%$ versus $2.16 \%$ in the data. This particular model prediction is more in line with data from Japan than the United States. But as shown in the next column of Table 2, the mean 4-quarter inflation rate increases to $1.41 \%$ if $r_{t}^{*}$ is allowed to dip further into negative territory during the simulations. Recall that the long-run endpoint of $\pi_{t}$ in the deflation equilibrium is $-r_{t}^{*}$. Allowing for more negative values of $r_{t}^{*}$ therefore serves to increase the mean inflation rate in both the deflation equilibrium and the switching model. The wide confidence intervals surrounding empirical estimates of $r$-star would not rule out true values that are more negative. When $r_{t}^{*} \in[-0.02,0.02]$, the ZLB binding frequency increases to $28.3 \%$, which is now higher than the U.S. data value of $24.2 \%$.

The mean forecast weight $\mu_{t}$ in the baseline switching model simulation is 0.73 with a standard deviation of 0.27 . Given these statistics, the value of $\mu_{t}$ can often fluctuate near 1

\footnotetext{
${ }^{21}$ The corresponding statistics from simulations of the targeted equilibrium and the deflation equilibrium are provided in Supplementary Appendix E.
} 
or 0 for sustained intervals. Smaller values for the window length $T_{w}$ that is used to compute the RMSFE statistic from equation (15) serve to increase the frequency of forecast switches towards the deflation equilibrium. For example, when $T_{w}=4$, the mean value of $\mu_{t}$ declines to 0.62 , the ZLB binding frequency increases to $25.2 \%$, the average ZLB duration increases to 16.1 quarters, and the mean value of $\pi_{4, t}$ decreases to $0.48 \%$.

Recall that the interest rate smoothing term can be interpreted as a form of forward guidance to keep $i_{t}^{*}$ "lower for longer" whenever the ZLB becomes binding. The presence of this guidance in the baseline simulation with $\rho=0.8$ serves to reduce the ZLB binding frequency relative to the $\rho=0$ case. Setting $\rho=0$ delivers a higher ZLB binding frequency of $24 \%$, but the ZLB episodes exhibit a shorter duration of 5.4 quarters on average.

The last column of Table 2 shows the results of a simulation where $g_{r}=1.5$, analogous to the counterfactual exercise in Section 4.4. Relative to the baseline simulation with $g_{r}=0$, introducing a direct policy response to the natural rate gap serves to increase the mean weight $\mu_{t}$ assigned to the targeted forecast rules and reduces the volatilities of $y_{t}$ and $\pi_{4, t}$. The ZLB binding frequency is slightly decreased and the episodes exhibit a shorter duration on average.

Using data from all advanced economies since 1950, Dordal-i-Carrera et al. (2016) estimate an average ZLB binding frequency of $7.5 \%$ and an average duration for ZLB episodes of 14 quarters. Excluding the high inflation period from 1968 to 1984 serves to raise the average ZLB binding frequency and the average ZLB duration to $10 \%$ and 18 quarters, respectively. For the period of consistent U.S. monetary policy since 1988, the single ZLB episode lasted 29 quarters.

Figure 7 plots the distribution of ZLB durations in the switching model versus the corresponding distributions in the two local equilibria. Unlike the targeted equilibrium, the switching model can produce infrequent and long-lived ZLB episodes in response to small, normally distributed shocks. The average ZLB duration in the switching model is 12.9 quarters, with a maximum observed duration in the simulation of 166 quarters. From Figure 7, we see that a 29 quarter ZLB episode is an extremely rare event in the targeted equilibrium but can occur with about $5 \%$ frequency in the switching model. To account for infrequent and long-lived ZLB episodes in the targeted equilibrium, Dordal-i-Carreras, et al. (2016) develop 
a model with large, infrequent, and long-lived shocks.

\subsection{Effect of raising the inflation target}

In a press conference held on June 14, 2017, Fed Chair Janet Yellen stated that determining the appropriate level of the inflation target "is one of the most important questions facing monetary policy around the world in the future." Numerous authors make the case for a higher inflation target using frameworks that ignore the deflation equilibrium. ${ }^{22}$ This methodology may understate the benefits of a higher inflation target because the analysis does not take into account the possibility that a higher target could help prevent switching to the volatile deflation equilibrium where recessions are more severe. Aruoba and Schorfheide (2016) examine the welfare implications of a $4 \%$ inflation target in a framework that does consider the possibility of switching to the deflation equilibrium via an exogenous sunspot shock. They conclude (p. 395) that "the case for a higher inflation target is not particularly strong." It's worth noting, however, that the probability of switching to the deflation equilibrium in the Aruoba-Schorfheide model is invariant to changes in the inflation target. In contrast, the framework developed here has the potential to reduce the probability of switching to the deflation equilibrium.

Table 3 shows the effects of raising the central bank's inflation target when either $g_{r}=0$ or $g_{r}=1.5$. In both cases, raising $\pi^{*}$ reduces the ZLB binding frequency and the mean duration of ZLB episodes. Higher values of $\pi^{*}$ serve to reduce the volatility of $y_{t}$ because the volatile deflation equilibrium is now avoided more often. But at the same time, higher values of $\pi^{*}$ serve to increase the volatility of $\pi_{4, t}$. This is because higher values of $\pi^{*}$ widen the spread between the two inflation distributions implied by the two local equilibria. This causes the mean inflation rate to shift by a larger amount when a forecast switch inevitably does occur.

From Table 3 we see that an increase in $\pi^{*}$ can reduce, but not eliminate, the endogenous switches towards the deflation equilibrium. Even with an inflation target of $4 \%$, the ZLB binding frequency remains relatively high at around $8 \%$ and the average duration of a ZLB episode is 10 to 12 quarters. Once the possibility of switching to the deflation equilibrium

\footnotetext{
${ }^{22}$ See, for example, Blanchard, Dell'Ariccia, and Mauro (2010), Ball and Mazumder (2011), and Ball (2013).
} 
is taken into account, raising the inflation target appears to be a less effective solution for avoiding long-lived ZLB episodes.

Coibion, Gorodnichenko, and Wieland (2012) calibrate their model to deliver a ZLB binding frequency equal to that observed in U.S. data going back to the year 1950. From the start of 1950 to 2017.Q4, the ZLB was binding in 29 out of 272 quarters, or $10.7 \%$ of the time. The average CPI inflation rate in U.S. data since 1950 is around 4\%. Table 3 shows that the switching model with $\pi^{*}=0.04$ delivers a ZLB binding frequency of about $8 \%$-reasonably close to the U.S. value of $10.7 \%$ going back to 1950. Taking into account the micro-founded welfare costs of positive and variable inflation, Coibion, Gorodnichenko, and Wieland (2012) compute an optimal inflation rate for their model which is relatively low, less than $2 \%$ per year. Their analysis is extended by Dordal-i-Carrera, et al. (2016) who modify the shock process in the model to match the now-higher ZLB binding frequency implied by additional years of data for the U.S. and other advanced economies. The optimal inflation rate for the modified model lies in the range of $2.5 \%$ to $4 \%$.

Following Kiley and Roberts (2017), a simple loss function approach can be used to quantify the various trade-offs that are involved in raising the inflation target. The trade-offs here include: (1) reducing the likelihood of endogenous switches towards the volatile deflation equilibrium and thereby lowering the ZLB binding frequency, (2) inducing shifts in the volatilities of inflation and the output gap, and (3) introducing economic distortions that come from a higher average inflation. The loss function takes the form

$$
\text { Loss }=E\left\{\left[\pi_{4, t}-0.02\right]^{2}+\left[y_{t}-0.02(1-\beta) / \kappa\right]^{2}\right\}
$$

where the values 0.02 and $0.02(1-\beta) / \kappa$ are the targeted endpoints when $\pi^{*}=0.02$. The presumption is that the central bank in the baseline calibration with $\pi^{*}=0.02$ has chosen to target the "optimal" levels of $\pi_{4, t}$ and $y_{t}$. Hence, any shift away from the original target values when adopting $\pi^{*}>0.02$ would introduce economic distortions that are taken into account by the loss function.

Table 3 shows that the loss value is reduced in going from $\pi^{*}=0.02$ to $\pi^{*}=0.03$ when either $g_{r}=0$ or $g_{r}=1.5$. For any given value of $\pi^{*}$, the loss value is reduced in going from $g_{r}=0$ to $g_{r}=1.5$. Notice, however, that the magnitudes of the various loss reductions are 
relatively minor. It should be noted that this analysis does not consider any potential loss of central bank credibility that might arise from an upward shift in the inflation target. Overall, it would appear that the net gains from raising the inflation target in the switching model are small — consistent with the conclusions of Aruoba and Schorfheide (2016).

\section{Conclusion}

Standard New Keynesian models subject to a ZLB constraint exhibit two long-run endpoints (steady states) that are associated with two local equilibria. Most studies employing New Keynesian models focus solely on the targeted equilibrium and ignore the deflation equilibrium. But there appears to be no clear theoretical or empirical reason why the deflation equilibrium should be ruled out. Indeed, Bullard (2010) concludes that by "promising to remain at zero for a long time," central banks may inadvertently coordinate private-sector expectations so as to become stuck in the deflation equilibrium.

I examine a version of the New Keynesian model with a time-varying $r$-star and endogenous forecast switching based on past performance. The model can produce severe recessions and long-lived ZLB episodes when the short-run natural rate of interest remains persistently below $r$-star, implying a negative natural rate gap. This situation puts downward pressure on the output gap and inflation, inducing the representative agent to place increased weight on the deflation equilibrium forecast rules. Escape from the deflation equilibrium occurs endogenously when the natural rate gap eventually turns positive. But even in normal times, a non-trivial weight assigned to the deflation equilibrium forecast rules may cause the central bank to undershoot its inflation target and magnify the volatilities of macro variables relative to the targeted equilibrium.

I show that the switching model can exactly replicate the observed time paths of the U.S. output gap, quarterly PCE inflation, and the federal funds rate since 1988. The replication exercise tells us that the U.S. data since the start of the ZLB episode in 2008.Q4 are best described as a time-varying mixture of the targeted equilibrium and the deflation equilibrium.

Simulations with the model suggest that: (1) including a direct response to the natural rate gap in the monetary policy rule can result in improved economic outcomes and (2) raising the 
inflation target can reduce, but not eliminate, the endogenous switches towards the deflation equilibrium.

\section{References}

Arifovic, J., Schmitt-Grohé, S., Uribe, M., 2018. Learning to live in a liquidity trap. Journal of Economic Dynamics and Control 89, 120-136.

Armenter, R., 2018. The perils of nominal targets. Review of Economic Studies 85, 50-86.

Aruoba, S.B., 2019. Term structures of inflation expectations and real interest rates. Journal of Economic Business and Statistics, forthcoming.

Aruoba, S.B., Cuba-Borda, P., Schorfheide, F., 2018. Macroeconomic dynamics near the ZLB: A tale of two countries. Review of Economic Studies 85, 87-118.

Aruoba, S.B., Schorfheide, F., 2016. Inflation during and after the zero lower bound. In: Proceedings of 2015 Federal Reserve Bank of Kansas City Economic Policy Symposium, Inflation Dynamics and Monetary Policy, pp. 359-436.

Ball, L., Mazumder, S., 2011. Inflation dynamics and the Great Recession. Brookings Papers on Economic Activity, Spring, 337-402.

Ball L., 2013. The case for four percent inflation. Central Bank Review 13, 17-31.

Barsky, R., Justiniano, A., Melosi, L., 2014. The natural rate of interest and its usefulness for monetary policy. American Economic Review: Papers \& Proceedings 104(5), 37-43.

Benhabib, J., Schmitt-Grohé, S., Uribe, M., 2001a. Monetary policy and multiple equilibria. American Economic Review 91, 167-186.

Benhabib, J., Schmitt-Grohé, S., Uribe, M., 2001b. The perils of Taylor rules. Journal of Economic Theory 96, 40-69.

Bernanke, B.S., 2017. Monetary policy in a new era. Paper presented at conference on "Rethinking Macroeconomic Policy," Peterson Institute, Washington

DC, (October 12-13).

Blanchard, O., Dell'Ariccia, G., Mauro, P., 2010. Rethinking macroeconomic policy. Journal of Money, Credit and Banking 42(s1), 199-215. 
Bomfim, A.N., 2001. Measurement error in general equilibrium: The aggregate effects of noisy economic indicators. Journal of Monetary Economics 48, 585-603.

Bullard, J., 2010. Seven faces of "the peril." Federal Reserve Bank of St. Louis, Review, September/October, 92, 339-352.

Campbell, J.Y., Mankiw, N.G., 1989. Consumption, income, and interest rates: Reinterpreting the time series evidence. In: Blanchard, O.J., Fischer, S. (Eds.), NBER Macroeconomics Annual 1989, Volume 4. MIT Press, Cambridge MA, pp. 185-246.

Chung, H., Laforte, J.-P., Reifschneider, D., Williams, J.C., 2012. Have we underestimated the likelihood and severity of zero lower bound events? Journal of Money, Credit and Banking $44,47-82$.

Christiano, L.J., Eichenbaum, M., Johannsen, B.K., 2018. Does the new Keynesian model have a uniqueness problem? National Bureau of Economic Research, Working Paper No. 24612.

Coibion, O., Gorodnichenko, Y., Wieland, J., 2012. The optimal inflation rate in new Keynesian models: Should central banks raise their inflation targets in light of the zero lower bound? Review of Economic Studies 79, 1371-1406.

Coibion, O., Gorodnichenko, Y., 2015. Is the Phillips curve alive and well after all? Inflation expectations and the missing disinflation. American Economic Journal: Macroeconomics 7, 197-232.

Cúrdia, V., 2015. Why so slow? A gradual return for interest rates. Federal Reserve Bank of San Francisco Economic Letter 2015-32 (October 13).

Cúrdia, V., A. Ferrero, G.C. Ng, and A. Tambalotti 2015. Has U.S. monetary policy tracked the efficient interest rate? Journal of Monetary Economics 70, 72-83.

Del Negro, M., Giannone, D., Giannoni, M.P., Tambalotti, A., 2017. Safety, liquidity, and the natural rate of interest. Brookings Papers on Economic Activity (Spring), 235-294.

Dordal-i-Carreras, M., O. Coibion, Y. Gorodnichenko, J. Wieland 2016. Infrequent but longlived zero-bound episodes and the optimal rate of inflation. Annual Review of Economics 8, 497-520. 
Dudley, W.C., 2015. The U.S. economic outlook and monetary policy. Remarks at the Economic Club of New York, New York City (November 12).

Eggertsson, G.B., Mehrotra, N.R., Robbins, J.A., 2019. A model of secular stagnation: Theory and quantitative evaluation. American Economic Journal: Macroeconiomics 11, 1-48.

Fischer, S., 2016., Monetary policy, financial stability, and the zero lower bound. Remarks at the Annual Meeting of the American Economic Association, San Francisco, California (January 3).

Gelain, P., Lansing, K.J., Natvik, G.J., 2018. Explaining the boom-bust cycle in the U.S. housing market: A reverse-engineering approach. Journal of Money Credit and Banking 50, 1751-1782.

Gust, C.J., Johannsen, B.K., López-Salido, D., 2017. Monetary policy, incomplete information, and the zero lower bound. IMF Economic Review 65, 37-70.

Hamilton, J.D., Harris, E.S., Hatzius, J., West, K.D., 2016. The equilibrium real funds rate: Past, present and future. IMF Economic Review 64, 660-707.

Haubrich, J.G., Pennacchi, G., Ritchken, P., 2012. Inflation expectations, real rates, and risk premia: Evidence from inflation swaps. Review of Financial Studies 25, 1588-1629.

Hills, T.S., Nakata, T., Schmidt, S., 2019. Effective lower bound risk. Federal Reserve Board, Finance and Economics Discussion Series Paper 2019-077.

Jørgensen, P.L., Lansing, K.J., 2019. Anchored inflation expectations and the flatter Phillips curve. Federal Reserve Bank of San Francisco, Working Paper 2019-27.

Kiley, M.T., 2019. The global equilibrium real interest rate: Concepts, estimates and challenges. Federal Reserve Board, Finance and Economics Discussion Series Paper 2019-076.

Kiley, M.T. and J.M. Roberts 2017. Monetary policy in a low interest rate world. Brookings Papers on Economic Activity (Spring), 317-372.

Kozicki, S., Tinsley, P.A., 2012. Effective use of survey information in estimating the evolution of expected inflation. Journal of Money Credit and Banking 44, 145-169.

Lansing, K.J., 2009. Time-varying U.S. inflation dynamics and the new Keynesian Phillips 
curve. Review of Economic Dynamics 12, 304-326.

Lansing, K.J., 2016. Projecting the long-run natural rate of interest. Federal Reserve Bank of San Francisco Economic Letter 2016-25 (August 29).

Lansing, K.J., 2019. Real business cycles, animal spirits, and stock market valuation. International Journal of Economic Theory 15, 77-94.

Lansing, K.J., LeRoy, S.F., 2014. Risk aversion, investor information, and stock market volatility. European Economic Review 70, 88-107.

Lansing, K.J., Markiewicz, A., 2018. Top incomes, rising inequality, and welfare. Economic Journal 128, 262-297.

Laubach, T., Williams, J.C., 2016. Measuring the natural rate of interest redux. Business Economics 51, 257-267.

Lorenzoni, G., 2009. A theory of demand shocks. American Economic Review 99, 2050-2084. Lubik, T.A. Matthes, C., 2015. Calculating the natural rate of interest: A comparison of two alternative approaches. Federal Reserve Bank of Richmond, Economic Brief (October 15).

McCallum, B., 1999. Role of the minimal state variable criterion in rational expectations models. International Tax and Public Finance 6, 621-639.

McKay, A., Nakamura, E., Steinsson, J., 2017. The discounted Euler equation: A note. Economica 84, 820-831.

Mertens, K., Ravn, M.O., 2014. Fiscal policy in an expectations-driven liquidity trap. Review of Economic Studies 81, 1637-1667.

Nicolau, J., 2002. Processes that look like random walks: The bounded random walk process in discrete and continuous time. Econometric Theory 18, 99-118

Reifschneider, D., Williams, J.C., 2000. Three lessons for monetary policy in a low-inflation era. Journal of Money, Credit, and Banking 32, 936-966.

Richter, A.W., Throckmorton, N.A., 2016. Are nonlinear methods necessary at the zero lower bound? Federal Reserve Bank of Dallas, Working Paper 1606.

Sargent, T.J., 1999. The Conquest of American Inflation. Princeton University Press, Prince- 
ton.

Schmitt-Grohé, S., Uribe, M., 2010. The optimal rate of inflation. In: Friedman, B.M., Woodford M. (Eds.), Handbook of Monetary Economics, 1st Edition, Volume 3. Elsevier, San Diego, 653-722.

Stock, J.H., Watson, M.W., 2007. Why has inflation become harder to forecast? Journal of Money, Credit, and Banking, 39, 3-34.

Taylor, J.B., 1999. A historical analysis of monetary policy rules. In Taylor, J.B. (Ed.), Monetary policy rules. University of Chicago Press, Chicago, pp. 319-348.

Timmermann, A., 2006. Forecast combinations. In: Elliott, G., Granger, C., Timmermann A. (Eds.), Handbook of Economic Forecasting, Volume 1. Elsevier, Amsterdam, pp. 135-196. Uribe, M., 2018. The neo-Fisher effect: Econometric evidence from empirical and optimizing models. National Bureau of Economic Research, Working Paper 25089.

Yellen, J., 2015. Normalizing monetary policy: Prospects and perspectives. Remarks at "The New Normal for Monetary Policy," research conference sponsored by the Federal Reserve Bank of San Francisco, San Francisco, California (March 27). 


\section{A Appendix: Kalman filter estimate of $r$-star}

Straightforward computations using the laws of motion (3) and (4) yield the following expression for the unconditional variance of $\Delta r_{t} \equiv r_{t}-r_{t-1}$ :

$$
\operatorname{Var}\left(\Delta r_{t}\right)=\sigma_{\varepsilon}^{2}\left[\frac{\left(1-\rho_{r}\right) \phi+2}{1+\rho_{r}}\right]
$$

where $\phi \equiv \sigma_{\eta}^{2} / \sigma_{\varepsilon}^{2}$. Given the calibrated values of $\rho_{r}$ and $\lambda$ that fit the Laubach-Williams $r$-star series, the implied value of $\phi$ can be computed using the optimal Kalman gain formula (7). Given the value of $\phi$, the implied value of $\sigma_{\varepsilon}$ can be inferred from equation (A.1) using the observed value of $\operatorname{Var}\left(\Delta r_{t}\right)$ from the U.S. data. Given $\phi$ and $\sigma_{\varepsilon}$, we have $\sigma_{\eta}=\sigma_{\varepsilon} \sqrt{\phi}$.

Solving equation (3) for $r_{t}^{*}$ yields:

$$
r_{t}^{*}=\underbrace{\frac{r_{t}-\rho_{r} r_{t-1}}{1-\rho_{r}}}_{\text {Signal }}-\underbrace{\varepsilon_{t}}_{\text {Noise }},
$$

where the first term represents the signal and the second term represents the noise. Equation (4) shows that the Kalman filter estimate of $r_{t}^{*}$, denoted by $E_{t} r_{t}^{*}$, is a weighted average of the signal and the previous period's estimate $E_{t-1} r_{t-1}^{*}$, where the weight assigned to the signal is the Kalman gain parameter $\lambda$.

The one step ahead forecast error for $r_{t+1}$ is given by

$$
\begin{aligned}
e r r_{t+1} & =r_{t+1}-E_{t} r_{t+1} \\
& =r_{t+1}-\left[\rho_{r} r_{t}+\left(1-\rho_{r}\right) E_{t} r_{t}^{*}\right] \\
& =\varepsilon_{t+1}+\left(1-\rho_{r}\right) \eta_{t+1}+\left(1-\rho_{r}\right)\left(r_{t}^{*}-E_{t} r_{t}^{*}\right)
\end{aligned}
$$

where the last term in (A.3) represents the estimation error for $r_{t}^{*}$. The optimal value of $\lambda$ minimizes the mean squared forecast error, as given by

$$
E\left(e r r_{t+1}^{2}\right)=\sigma_{\varepsilon}^{2}\left[1+\left(1-\rho_{r}\right)^{2} \phi\right]+\left(1-\rho_{r}\right)^{2} \operatorname{Var}\left(r_{t}^{*}-E_{t} r_{t}^{*}\right)
$$

where $\operatorname{Var}\left(r_{t}^{*}-E_{t} r_{t}^{*}\right)$ is the unconditional variance of the estimation error.

The law of motion for the estimation error follows directly from equation (6) and can be written as

$$
r_{t}^{*}-E_{t} r_{t}^{*}=\lambda\left[\frac{z_{t}-\rho_{r} z_{t-1}}{1-\rho_{r}}\right]+(1-\lambda)\left(r_{t-1}^{*}-E_{t-1} r_{t-1}^{*}\right)-\left[\frac{1-\lambda-\rho_{r}}{1-\rho_{r}}\right] \eta_{t},
$$


where $z_{t} \equiv r_{t}-r_{t}^{*}$ is the true natural rate gap. The law of motion for $z_{t}$ follows directly from equations (3) and (4) and can be written as

$$
z_{t}=\rho_{r} z_{t-1}-\rho_{r} \eta_{t}+\varepsilon_{t}
$$

Starting from equations (A.5) and (A.6), we can compute the following expression for the unconditional variance of the estimation error

$$
\operatorname{Var}\left(r_{t}^{*}-E_{t} r_{t}^{*}\right)=\sigma_{\varepsilon}^{2}\left\{\frac{\lambda\left(\rho_{r}^{2} \phi+1\right)+\left(1-\lambda-\rho_{r}\right)\left[(1-\lambda)\left(1-\rho_{r}\right) / \lambda+\rho_{r}\right] \phi}{(2-\lambda)\left(1-\rho_{r}\right)^{2}}\right\},
$$

which can be substituted into equation (A.4) to obtain a complicated expression for $E\left(e r r_{t+1}^{2}\right)$ in terms of $\lambda$. From this expression, we can compute the gradient

$$
\frac{\partial E\left(e r r_{t+1}^{2}\right)}{\partial \lambda}=\frac{2\left[\lambda^{2}-(1-\lambda)\left(1-\rho_{r}\right)^{2} \phi\right]}{(2-\lambda)^{2} \lambda^{2}} .
$$

Setting the gradient equal to zero yields a quadratic equation in $\lambda$. The root that minimizes $E\left(e r r_{t+1}^{2}\right)$ is given by equation (7) in the text.

\section{B Appendix: Targeted equilibrium}

To solve for the local linear forecast rules associated with the targeted equilibrium, I assume that $i_{t}^{*}=i_{t}>0$ for all $t$. This assumption is valid in a vicinity of the targeted equilibrium's long-run endpoints. Starting from equation (10) we have:

$$
\begin{array}{r}
i_{t}^{*}=\rho i_{t-1}^{*}+(1-\rho)\left[E_{t} r_{t}^{*}+\pi^{*}+g_{\pi} \omega\left(\pi_{t}-\pi^{*}\right)+g_{\pi}(1-\omega)\left(\bar{\pi}_{t-1}-\pi^{*}\right)\right. \\
\left.+g_{y}\left(y_{t}-y^{*}\right)+g_{r}\left(r_{t}-E_{t} r_{t}^{*}\right)\right]
\end{array}
$$

where I have used equation (11) to eliminate $\bar{\pi}_{t}$.

When $i_{t}^{*}=i_{t}>0$, equation (B.1) together with the Euler equation (1) and the Phillips curve (2) form a linear system of three equations in the three unknown decision rules for $y_{t}$, $\pi_{t}$, and $i_{t}^{*}$. The state variables are: $r_{t}, E_{t} r_{t}^{*}, \bar{\pi}_{t-1}, i_{t-1}^{*}, \nu_{t}$, and $u_{t}$. Standard techniques yield a set of linear decision rules of the form

$$
\left[\begin{array}{l}
y_{t}-\pi^{*}(1-\beta) / \kappa \\
\pi_{t}-\pi^{*} \\
i_{t}^{*}-\left(E_{t} r_{t}^{*}+\pi^{*}\right)
\end{array}\right]=\mathbf{A}\left[\begin{array}{l}
r_{t}-E_{t} r_{t}^{*} \\
\bar{\pi}_{t-1}-\pi^{*} \\
i_{t-1}^{*}-E_{t} r_{t}^{*}-\pi^{*} \\
\nu_{t} \\
u_{t}
\end{array}\right]
$$


where $\mathbf{A}$ is a $3 \times 5$ matrix of decision rule coefficients. For the parameter values shown in Table 1, the matrix $\mathbf{A}$ is

$$
\mathbf{A}=\left[\begin{array}{rrrrr}
0.638 & -0.155 & -0.386 & 3.844 & -0.178 \\
0.083 & -0.017 & -0.033 & 0.425 & 1.436 \\
0.139 & 0.130 & 0.718 & 0.826 & 0.161
\end{array}\right]
$$

Iterating the linear decision rules in (B.2) ahead one period and then taking the conditional expectation of both sides yields the following set of linear forecast rules associated with the targeted equilibrium:

$$
\begin{aligned}
\widehat{E}_{t}^{\operatorname{targ}} y_{t+1}= & y^{*}+\mathbf{A}_{11} \rho_{r}\left(r_{t}-E_{t} r_{t}^{*}\right)+\mathbf{A}_{12}\left(\bar{\pi}_{t}-\pi^{*}\right)+\mathbf{A}_{13}\left(i_{t}^{*}-E_{t} r_{t}^{*}-\pi^{*}\right)+ \\
& \mathbf{A}_{14} \rho_{\nu} \nu_{t}+\mathbf{A}_{15} \rho_{u} u_{t}, \\
\widehat{E}_{t}^{\operatorname{targ}} \pi_{t+1}= & \pi^{*}+\mathbf{A}_{21} \rho_{r}\left(r_{t}-E_{t} r_{t}^{*}\right)+\mathbf{A}_{22}\left(\bar{\pi}_{t}-\pi^{*}\right)+\mathbf{A}_{23}\left(i_{t}^{*}-E_{t} r_{t}^{*}-\pi^{*}\right)+ \\
& \mathbf{A}_{24} \rho_{\nu} \nu_{t}+\mathbf{A}_{25} \rho_{u} u_{t},
\end{aligned}
$$

where $\mathbf{A}_{i j}$ represents the corresponding element of the matrix $\mathbf{A}$ and I have substituted in $E_{t}\left(r_{t+1}-E_{t+1} r_{t+1}^{*}\right)=\rho_{r}\left(r_{t}-E_{t} r_{t}^{*}\right)$. Notice that the forecast rules depend on the realization of $\pi_{t}$ because $\bar{\pi}_{t}$ depends on $\pi_{t}$ via equation (11). Also, the forecast rules depend on the realization of $i_{t}^{*}$ due to the interest rate smoothing term in (B.1). Hence, the model solution allows for simultaneity between the agent's forecasts and the realized values of $\pi_{t}$ and $i_{t}^{*}$.

The local linear forecast rules (B.4) and (B.5) are derived under the assumption that $i_{t}^{*}=i_{t}>0$. However, in the stochastic simulation of the targeted equilibrium, I allow for an occasionally binding ZLB. When simulating the model, I substitute the local linear forecast rules given by (B.4) and (B.5) into the global equilibrium conditions (1) and (2). Together with the monetary policy rule (B.1) and the ZLB constraint (12), this procedure yields a system of four equations that are solved each period to obtain the four realizations $y_{t}, \pi_{t}, i_{t}^{*}$, and $i_{t}$.

\section{Appendix: Deflation equilibrium}

To solve for the local linear forecast rules associated with the deflation equilibrium, I assume $i_{t}^{*} \leq 0$ such that $i_{t}=0$ for all $t$. This assumption is valid in a vicinity of the deflation equilibrium's long-run endpoints. Equation (B.1) applies unchanged to the deflation equilibrium, 
as does the Phillips curve (2). However, due to the binding ZLB, the Euler equation (1) now becomes

$$
y_{t}=E_{t} y_{t+1}+\alpha\left[E_{t} \pi_{t+1}+r_{t}\right]+\nu_{t} .
$$

When $i_{t}=0$, equation (C.1) together with equations (B.1) and (2) form a linear system of three equations in the three unknown decision rules for $y_{t}, \pi_{t}$, and $i_{t}^{*}$. The state variables are: $r_{t}, E_{t} r_{t}^{*}, \bar{\pi}_{t-1}, i_{t-1}^{*}, \nu_{t}$, and $u_{t}$. The minimum state variable (MSV) solution yields a set of linear decision rules of the form

$$
\left[\begin{array}{l}
y_{t}-\left(-E_{t} r_{t}^{*}\right)(1-\beta) / \kappa \\
\pi_{t}-\left(-E_{t} r_{t}^{*}\right) \\
i_{t}^{*}-\left(E_{t} r_{t}^{*}+\pi^{*}\right)\left[1-g_{\pi}-g_{y}(1-\beta) / \kappa\right]
\end{array}\right]=\mathbf{B}\left[\begin{array}{l}
r_{t}-E_{t} r_{t}^{*} \\
\bar{\pi}_{t-1}-\left(-E_{t} r_{t}^{*}\right) \\
i_{t-1}^{*}-\left(E_{t} r_{t}^{*}+\pi^{*}\right)\left[1-g_{\pi}-g_{y}(1-\beta) / \kappa\right] \\
\nu_{t} \\
u_{t}
\end{array}\right],
$$

where $\mathbf{B}$ is a $3 \times 5$ matrix of constant coefficients. The MSV solution implies $\mathbf{B}_{12}=\mathbf{B}_{22}=0$ and $\mathbf{B}_{13}=\mathbf{B}_{23}=0$. For the parameter values shown in Table 1, the matrix $\mathbf{B}$ is

$$
\mathbf{B}=\left[\begin{array}{ccccc}
1.505 & 0 & 0 & 7.732 & 0.104 \\
0.291 & 0 & 0 & 1.253 & 1.471 \\
0.341 & 0.163 & 0.8 & 1.718 & 0.222
\end{array}\right]
$$

Comparing the first column of matrix $\mathbf{B}$ in (C.3) to the first column of matrix $\mathbf{A}$ in (B.3) shows that a shock to the natural rate gap $r_{t}-E_{t} r_{t}^{*}$ will be transmitted more forcefully to macro variables in the deflation equilibrium than in targeted equilibrium. Specifically, we have

$$
\frac{\mathbf{B}_{11}}{\mathbf{A}_{11}}=2.4, \quad \frac{\mathbf{B}_{21}}{\mathbf{A}_{21}}=3.5, \quad \frac{\mathbf{B}_{31}}{\mathbf{A}_{31}}=2.5 .
$$

For the special case when $\rho=g_{r}=0$ and $\omega=1$, it is straightforward to derive the following analytical relationship between the decision rule coefficients for the two local equilibria:

$$
\frac{\mathbf{B}_{11}}{\mathbf{A}_{11}}=\frac{\mathbf{B}_{21}}{\mathbf{A}_{21}}=\frac{\mathbf{B}_{31}}{\mathbf{A}_{31}}=1+\frac{\alpha\left[\kappa g_{\pi}+\left(1-\beta \rho_{r}\right) g_{y}\right]}{\left(1-\beta \rho_{r}\right)\left(1-\rho_{r}\right)-\alpha \kappa \rho_{r}}>1 .
$$

Iterating the linear decision rules in (C.2) ahead one period and then taking the conditional expectation of both sides yields the following set of local linear forecast rules for the deflation equilibrium:

$$
\begin{aligned}
& \widehat{E}_{t}^{\text {defl }} y_{t+1}=-E_{t} r_{t}^{*}(1-\beta) / \kappa+\mathbf{B}_{11} \rho_{r}\left(r_{t}-E_{t} r_{t}^{*}\right)+\mathbf{B}_{14} \rho_{\nu} \nu_{t}+\mathbf{B}_{15} \rho_{u} u_{t}, \\
& \widehat{E}_{t}^{\text {defl }} \pi_{t+1}=-E_{t} r_{t}^{*}+\mathbf{B}_{21} \rho_{r}\left(r_{t}-E_{t} r_{t}^{*}\right)+\mathbf{B}_{24} \rho_{\nu} \nu_{t}+\mathbf{B}_{25} \rho_{u} u_{t}
\end{aligned}
$$


where the MSV solution implies $\mathbf{B}_{12}=\mathbf{B}_{22}=0$ and $\mathbf{B}_{13}=\mathbf{B}_{23}=0$ and I have substituted in $E_{t}\left(r_{t+1}-E_{t+1} r_{t+1}^{*}\right)=\rho_{r}\left(r_{t}-E_{t} r_{t}^{*}\right)$.

The local linear forecast rules (C.6) and (C.7) are derived under the assumption that $i_{t}=0$. However, in the stochastic simulation of the deflation equilibrium, I allow for an occasionally slack ZLB. When simulating the model, I substitute the local linear forecast rules given by (C.6) and (C.7) into the global equilibrium conditions (1) and (2). Together with the monetary policy rule (B.1) and the ZLB constraint (12), this procedure yields a system of four equations that are solved each period to obtain the four realizations $y_{t}, \pi_{t}, i_{t}^{*}$, and $i_{t}$.

\section{Appendix: Simplified model}

This appendix provides closed-form expressions for the decision rules associated with each of the two local equilibria in the simplified model that is used in Section 4.1. Starting from the original model, the simplified model imposes $\rho=0, \omega=1, \sigma_{\nu}=0, \sigma_{u}=0$, and $\sigma_{\eta}=0$. Under these settings, $i_{t-1}^{*}$ and $\bar{\pi}_{t-1}$ drop out as state variables, the shocks $\nu_{t}$ and $u_{t}$ are zero for all $t$, and $r$-star is constant.

The targeted equilibrium decision rules are

$$
\left[\begin{array}{l}
y_{t}-\pi^{*}(1-\beta) / \kappa \\
\pi_{t}-\pi^{*} \\
i_{t}^{*}-\left(r^{*}+\pi^{*}\right)
\end{array}\right]=\mathbf{A}\left[r_{t}-r^{*}\right],
$$

where the elements of the matrix $\mathbf{A}$ are given by

$$
\mathbf{A}=\left[\begin{array}{c}
\frac{\alpha\left(1-\beta \rho_{r}\right)\left(1-g_{r}\right)}{\left(1-\rho_{r}+\alpha g_{y}\right)\left(1-\beta \rho_{r}\right)+\alpha \kappa\left(g_{\pi}-\rho_{r}\right)} \\
\frac{\alpha \kappa\left(1-g_{r}\right)}{\left(1-\rho_{r}+\alpha g_{y}\right)\left(1-\beta \rho_{r}\right)+\alpha \kappa\left(g_{\pi}-\rho_{r}\right)} \\
g_{r}+\frac{\left[\alpha \kappa g_{\pi}+\alpha g_{y}\left(1-\beta \rho_{r}\right)\right]\left(1-g_{r}\right)}{\left(1-\rho_{r}+\alpha g_{y}\right)\left(1-\beta \rho_{r}\right)+\alpha \kappa\left(g_{\pi}-\rho_{r}\right)}
\end{array}\right],
$$

which shows that setting $g_{r}=1$ will completely stabilize $y_{t}$ and $\pi_{t}$ against fluctuations in the natural rate gap $r_{t}-r^{*}$. 
The deflation equilibrium decision rules are

$$
\left[\begin{array}{l}
y_{t}-\left(-r^{*}\right)(1-\beta) / \kappa \\
\pi_{t}-\left(-r^{*}\right) \\
i_{t}^{*}-\left(r^{*}+\pi^{*}\right)\left[1-g_{\pi}-g_{y}(1-\beta) / \kappa\right]
\end{array}\right]=\mathbf{B}\left[r_{t}-r^{*}\right],
$$

where the elements of the matrix $\mathbf{B}$ for the MSV solution are given by

$$
\mathbf{B}=\left[\begin{array}{c}
\frac{\alpha\left(1-\beta \rho_{r}\right)}{\left(1-\rho_{r}\right)\left(1-\beta \rho_{r}\right)-\alpha \kappa \rho_{r}} \\
\frac{\alpha \kappa}{\left(1-\rho_{r}\right)\left(1-\beta \rho_{r}\right)-\alpha \kappa \rho_{r}} \\
g_{r}+\frac{\alpha \kappa g_{\pi}+\alpha g_{y}\left(1-\beta \rho_{r}\right)}{\left(1-\rho_{r}\right)\left(1-\beta \rho_{r}\right)-\alpha \kappa \rho_{r}}
\end{array}\right] .
$$




\section{E Appendix: Supplementary Tables}

Table E.1. Unconditional Moments: Data versus Model

\begin{tabular}{lcccc}
\hline \hline & & & Model Simulations \\
& $\begin{array}{c}\text { U.S. Data } \\
\text { 1988.Q1-2017.Q4 }\end{array}$ & $\begin{array}{c}\text { Targeted } \\
\text { Equilibrium }\end{array}$ & $\begin{array}{c}\text { Deflation } \\
\text { Equilibrium }\end{array}$ & $\begin{array}{c}\text { Switching } \\
\text { Model }\end{array}$ \\
\hline \% periods $i_{t}=0$ & $24.2 \%$ & $1.08 \%$ & $79.3 \%$ & $15.8 \%$ \\
Mean ZLB duration & 29 qtrs. & 5.2 qtrs. & 37.9 qtrs. & 12.9 qtrs. \\
Max. ZLB duration & 29 qtrs. & 29 qtrs. & 375 qtrs. & 166 qtrs. \\
\hline Mean $y_{t}$ & $-1.37 \%$ & $0.40 \%$ & $-0.49 \%$ & $0.45 \%$ \\
Std. Dev. & $1.85 \%$ & $1.42 \%$ & $3.43 \%$ & $2.03 \%$ \\
Corr. Lag 1 & 0.95 & 0.79 & 0.86 & 0.83 \\
\hline Mean $\pi_{4, t}$ & $2.16 \%$ & $1.99 \%$ & $-2.18 \%$ & $0.92 \%$ \\
Std. Dev. & $1.10 \%$ & $0.91 \%$ & $1.62 \%$ & $1.52 \%$ \\
Corr. Lag 1 & 0.89 & 0.84 & 0.95 & 0.94 \\
\hline Mean $i_{t}^{*}$ & $3.04 \%$ & $4.17 \%$ & $-2.98 \%$ & $2.60 \%$ \\
Std. Dev. & $3.24 \%$ & $1.85 \%$ & $3.54 \%$ & $2.98 \%$ \\
Corr. Lag 1 & 0.99 & 0.98 & 0.98 & 0.99 \\
\hline
\end{tabular}

Notes: The ZLB episode in U.S. data is from 2008.Q4 through 2015.Q4. Model results are computed from a 300,000 period simulation. $\pi_{4, t} \equiv\left[\Pi_{j=0}^{3}\left(1+\pi_{t-j}\right)\right]^{0.25}-1$.

Table E.2. Properties of Representative Agent's Forecast Errors

\begin{tabular}{cccc}
\hline \hline \multirow{2}{*}{ Statistic } & \multicolumn{3}{c}{ Model Simulations } \\
& $\begin{array}{c}\text { Targeted } \\
\text { Equilibrium }\end{array}$ & $\begin{array}{c}\text { Deflation } \\
\text { Equilibrium }\end{array}$ & $\begin{array}{c}\text { Switching } \\
\text { Model }\end{array}$ \\
\hline $\operatorname{Corr}\left(\mathrm{err}_{t+1}^{y}, \mathrm{err}_{t}^{y}\right)$ & 0.001 & -0.006 & 0.019 \\
$\operatorname{Corr}\left(\mathrm{err}_{t+1}^{\pi}, \mathrm{err}_{t}^{\pi}\right)$ & 0.003 & 0.002 & 0.074 \\
$E\left(\mathrm{err}_{t+1}^{y}\right)$ & $-0.0001 \%$ & $-0.057 \%$ & $0.013 \%$ \\
$E\left(\mathrm{err}_{t+1}^{\pi}\right)$ & $-0.0027 \%$ & $-0.004 \%$ & $0.004 \%$ \\
$\sqrt{E\left[\left(\mathrm{err}_{t+1}^{y}\right)^{2}\right]}$ & $0.871 \%$ & $1.771 \%$ & $1.129 \%$ \\
$\sqrt{E\left[\left(\mathrm{err}_{t+1}^{\pi}\right)^{2}\right]}$ & $1.369 \%$ & $1.418 \%$ & $1.392 \%$ \\
\hline
\end{tabular}

Notes: Model results are computed from a 300,000 period simulation. 
Table 1. Baseline Parameter Values

\begin{tabular}{ccl}
\hline \hline Parameter & Value & \multicolumn{1}{c}{ Description/Target } \\
\hline$\alpha$ & 0.15 & Interest rate coefficient in Euler equation. \\
$\beta$ & 0.995 & Discount factor in Phillips curve. \\
$\kappa$ & 0.025 & Output gap coefficient in Phillips curve. \\
$\sigma_{\nu}$ & 0.003 & Std. dev. of demand shock. \\
$\sigma_{u}$ & 0.010 & Std. dev. of cost push shock. \\
$\rho_{\nu}$ & 0.85 & Persistence of demand shock. \\
$\rho_{u}$ & 0.32 & Persistence of cost push shock. \\
\hline$\pi^{*}$ & 0.02 & Fed inflation target. \\
$\omega$ & 0.456 & $\bar{\pi}_{t} \simeq$ 4-quarter inflation rate. \\
$g_{\pi}$ & 1.5 & Policy rule response to inflation. \\
$g_{y}$ & 1.0 & Policy rule response to output gap. \\
$g_{r}$ & 0.0 & Policy rule response to natural rate gap. \\
$\rho$ & 0.8 & Interest rate smoothing parameter. \\
\hline$\rho_{r}$ & 0.875 & Persistence parameter for $r_{t}$. \\
$\lambda$ & 0.015 & Kalman gain for $E_{t} r_{t}^{*}$. \\
$\sigma_{\varepsilon}$ & 0.0098 & Std. dev. of temporary shock to $r_{t}$. \\
$\sigma_{\eta}$ & 0.0012 & Std. dev. of permanent shock to $r_{t}$. \\
$T_{w}$ & 8 & Window length in qtrs. for forecast evaluation. \\
\hline
\end{tabular}


Table 2. Switching Model Simulations: Sensitivity Analysis

\begin{tabular}{lcccccc}
\hline \hline \multicolumn{1}{c}{ Statistic } & U.S. Data & Baseline & $r_{t}^{*} \in[-0.02,0.02]$ & $T_{w}=4$ & $\rho=0$ & $g_{r}=1.5$ \\
\hline \% periods $i_{t}=0$ & $24.2 \%$ & $15.8 \%$ & $28.3 \%$ & $25.2 \%$ & $24.0 \%$ & $15.2 \%$ \\
Mean ZLB duration & 29 qtrs. & 12.9 qtrs. & 12.2 qtrs. & 16.1 qtrs. & 5.4 qtrs. & 10.4 qtrs. \\
Max. ZLB duration & 29 qtrs. & 166 qtrs. & 148 qtrs. & 163 qtrs. & 100 qtrs. & 147 qtrs. \\
Mean $\mu_{t}$ & 0.76 & 0.73 & 0.70 & 0.62 & 0.69 & 0.77 \\
\hline Mean $y_{t}$ & $-1.37 \%$ & $0.45 \%$ & $0.30 \%$ & $0.29 \%$ & $0.20 \%$ & $0.48 \%$ \\
Mean $\pi_{4, t}$ & $2.16 \%$ & $0.92 \%$ & $1.41 \%$ & $0.48 \%$ & $0.74 \%$ & $1.10 \%$ \\
Mean $i_{t}^{*}$ & $3.04 \%$ & $2.60 \%$ & $1.05 \%$ & $1.79 \%$ & $2.09 \%$ & $2.91 \%$ \\
\hline Std. dev. $y_{t}$ & $1.85 \%$ & $2.03 \%$ & $2.18 \%$ & $2.39 \%$ & $2.12 \%$ & $1.55 \%$ \\
Std. dev. $\pi_{4, t}$ & $1.10 \%$ & $1.52 \%$ & $1.26 \%$ & $1.83 \%$ & $1.66 \%$ & $1.41 \%$ \\
Std. dev. $i_{t}^{*}$ & $3.24 \%$ & $2.98 \%$ & $2.70 \%$ & $3.65 \%$ & $3.87 \%$ & $3.27 \%$ \\
\hline
\end{tabular}

Notes: The sample period for the U.S. data is 1988.Q1 to 2017.Q4. The ZLB episode in U.S. data runs from 2008.Q4 through 2015.Q4. Model results are computed from a 300,000 period simulation. $\pi_{4, t} \equiv\left[\Pi_{j=0}^{3}\left(1+\pi_{t-j}\right)\right]^{0.25}-1$. 
Table 3. Effect of Raising the Inflation Target in Switching Model

\begin{tabular}{lcccc}
\hline \hline \multicolumn{1}{c}{ Statistic } & $\pi^{*}=0.02$ & $\pi^{*}=0.03$ & $\pi^{*}=0.04$ & $\pi^{*}=0.05$ \\
\hline$g_{r}=0$ & & & & \\
$\%$ periods $i_{t}=0$ & $15.8 \%$ & $11.5 \%$ & $7.6 \%$ & $4.7 \%$ \\
Mean ZLB duration & 12.9 qtrs. & 12.5 qtrs. & 12.4 qtrs. & 11.2 qtrs. \\
Max. ZLB duration & 166 qtrs. & 166 qtrs. & 165 qtrs. & 216 qtrs. \\
Mean $\mu_{t}$ & 0.73 & 0.75 & 0.77 & 0.79 \\
Std. dev. $y_{t}$ & $2.03 \%$ & $1.95 \%$ & $1.87 \%$ & $1.80 \%$ \\
Std. dev. $\pi_{4, t}$ & $1.52 \%$ & $1.60 \%$ & $1.65 \%$ & $1.68 \%$ \\
Std. dev. $i_{t}^{*}$ & $2.98 \%$ & $3.03 \%$ & $3.02 \%$ & $2.96 \%$ \\
$\sqrt{L o s s}$ & $2.76 \%$ & $2.55 \%$ & $2.65 \%$ & $3.06 \%$ \\
\hline$g_{r}=1.5$ & & & & \\
$\%$ periods $i_{t}=0$ & $15.2 \%$ & $11.1 \%$ & $7.7 \%$ & $5.3 \%$ \\
Mean ZLB duration & $10.4 \mathrm{qtrs}$. & $10.2 \mathrm{qtrs}$. & $9.9 \mathrm{qtrs}$. & $9.7 \mathrm{qtrs.}$ \\
Max. ZLB duration & $147 \mathrm{qtrs.}$ & $148 \mathrm{qtrs}$. & $148 \mathrm{qtrs.}$ & $147 \mathrm{qtrs}$. \\
Mean $\mu_{t}$ & 0.77 & 0.79 & 0.80 & 0.81 \\
Std. dev. $y_{t}$ & $1.55 \%$ & $1.50 \%$ & $1.46 \%$ & $1.41 \%$ \\
Std. dev. $\pi_{4, t}$ & $1.41 \%$ & $1.51 \%$ & $1.59 \%$ & $1.65 \%$ \\
Std. dev. $i_{t}^{*}$ & $3.27 \%$ & $3.30 \%$ & $3.31 \%$ & $3.29 \%$ \\
$\sqrt{L o s s}$ & $2.28 \%$ & $2.16 \%$ & $2.38 \%$ & $2.90 \%$ \\
\hline Note: Model results are computed from a 300,000 period simulation.
\end{tabular}


Figure 1: U.S. Nominal Interest Rates and Inflation

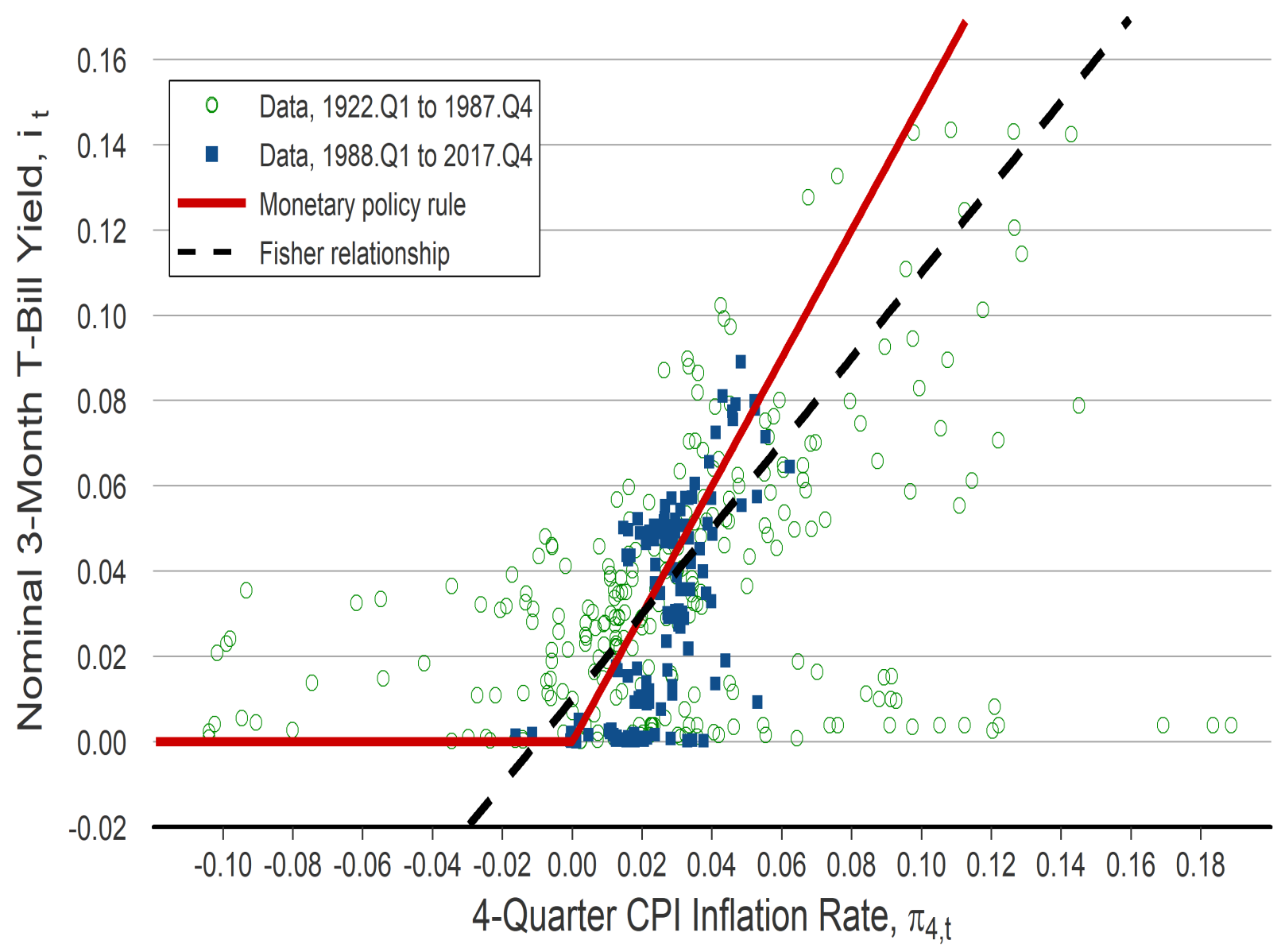

Notes: The two intersections of the ZLB-augmented monetary policy rule (solid red line) with the Fisher relationship (dashed black line) define two long-run endpoints. The monetary policy rule is $i_{t}=r^{*}+\pi^{*}+g_{\pi}\left(\pi_{4, t}-\pi^{*}\right)$ with $r^{*}=0.01, \pi^{*}=0.02$ and $g_{\pi}=1.5$. The Fisher relationship is $i_{t}=r^{*}+\pi_{4, t}$. 
Figure 2: Results for a Simplified Model

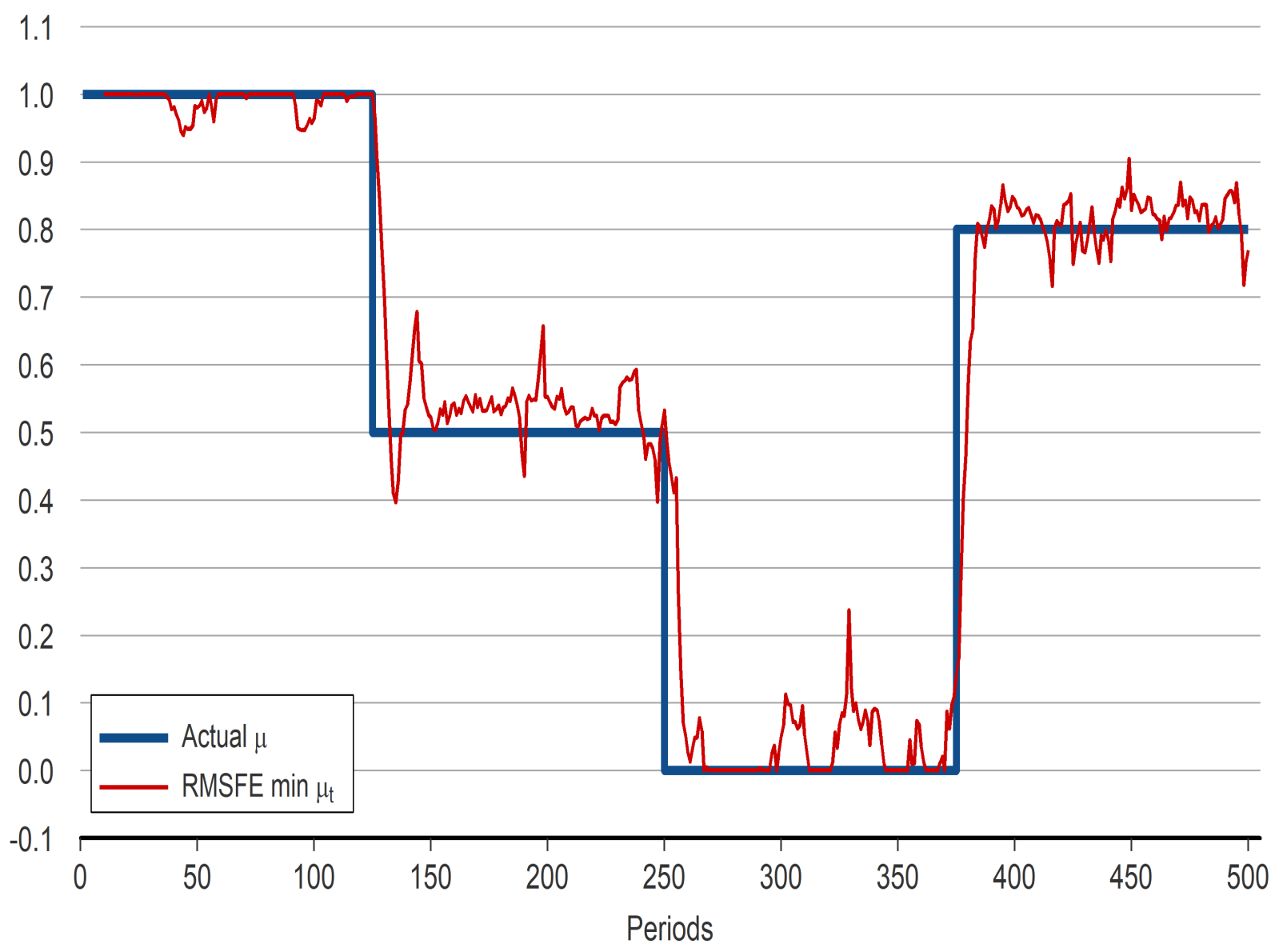

Notes: The simplified model imposes $\rho=0, \omega=1, \sigma_{\nu}=\sigma_{u}=0$, and $\sigma_{\eta}=0$. The model is used to generate data for $y_{t}$ and $\pi_{t}$ using an exogenous weight $\mu$ on the targeted forecast rules, where $\mu$ undergoes a series of infrequent shifts (thick blue line). The switching model's algorithm for determining the timevarying forecast weight $\mu_{t}$ is to minimize the $R M S F E$ statistic from equation (15) with $T_{w}=8$. Applying this algorithm to the simulated data for $y_{t}$ and $\pi_{t}$ produces a time series for the weight $\mu_{t}$ (thin red line). The switching model's algorithm for determining $\mu_{t}$ successfully tracks the actual value of $\mu$ that is being used to generate the data. 
Figure 3: U.S. Data
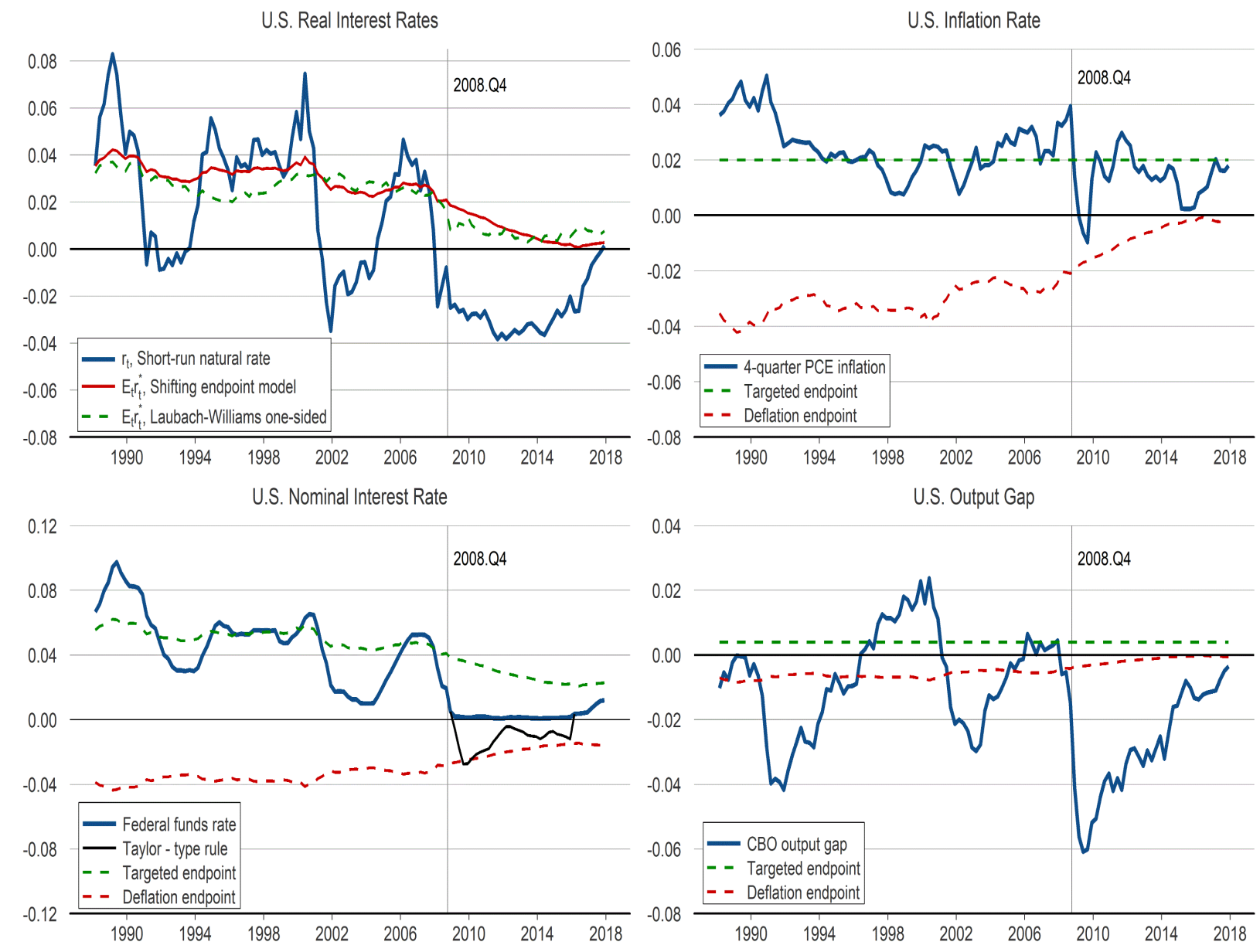

Notes: The short-run natural rate of interest $r_{t}$ remains below the model-implied value of $E_{t} r_{t}^{*}$ from 2007.Q4 onward, implying a negative natural rate gap. The nominal federal funds rate $i_{t}$ is approximately zero from 2008.Q4 through 2015.Q4. Assuming $i_{t}^{*}=i_{t}$ in 2008.Q4, the desired federal funds rate from 2009.Q1 through 2015.Q4 is computed using the calibrated policy rule (10). From 2016.Q1 onwards, I assume $i_{t}^{*}=i_{t}$. The top right panel shows that the 4-quarter PCE inflation rate was negative for three consecutive quarters in 2009 and is mostly below the Fed's 2\% inflation target from 2012.Q2 onward. The Great Recession was very severe, pushing the CBO output gap down to $-6.1 \%$ at the business cycle trough in 2009.Q2. The various endpoints plotted in the figure are computed using the expressions in Section 2.1, with $r_{t}^{*}$ set equal to the model-implied value of $E_{t} r_{t}^{*}$. 
Figure 4: Replicating U.S. Data with the Switching Model
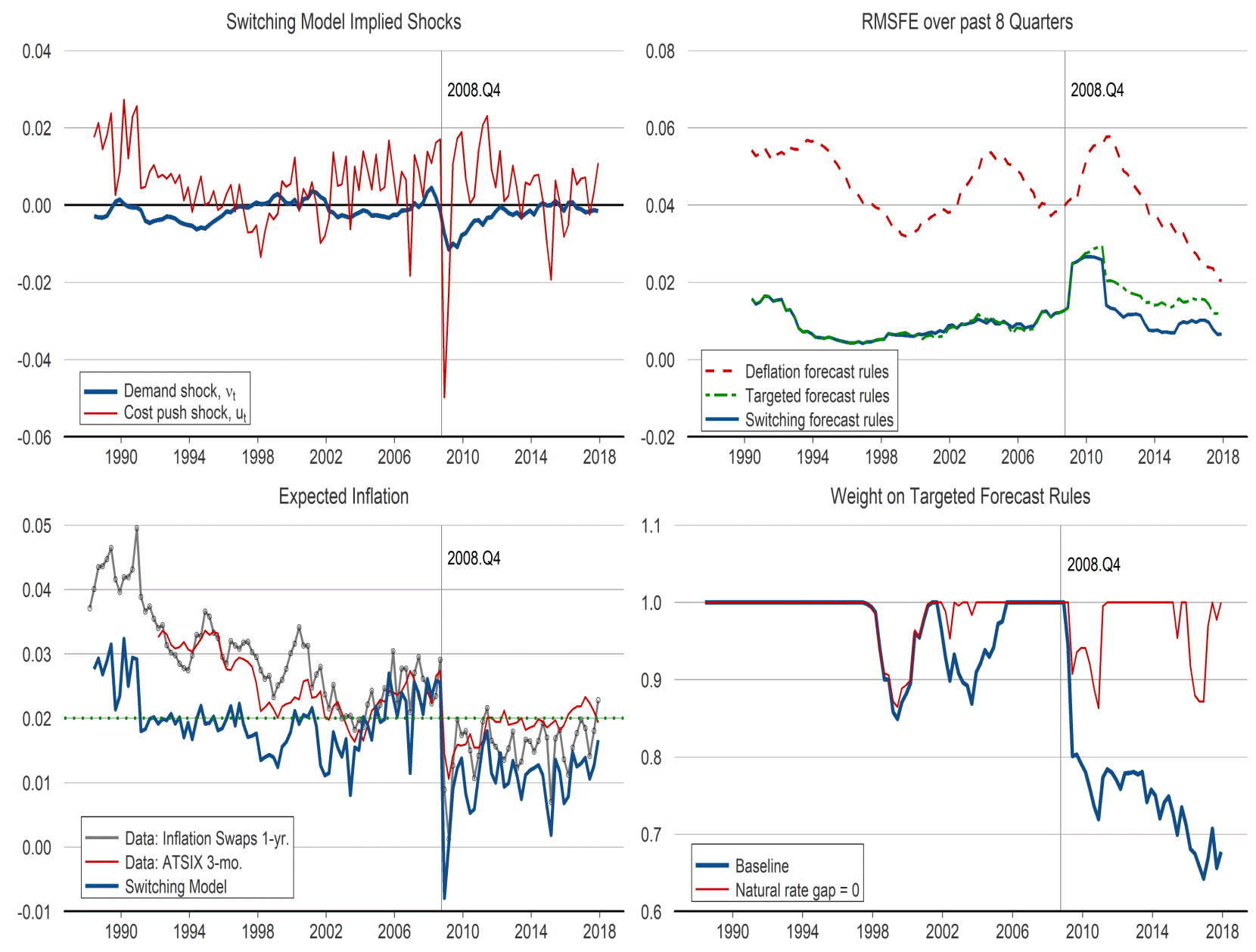

Notes: Given the U.S. data counterparts for the model variables, I solve for the implied time series of stochastic shocks and endogenous forecast rule weights that allow the switching model to exactly replicate the observed time paths of U.S. data. The model-implied shocks $\nu_{t}$ and $u_{t}$ go from positive to negative at the start of the ZLB episode in 2008.Q4. The top right panel shows that the performance gap between the two sets of forecast rules initially narrows with the onset of the ZLB episode in 2008.Q4. The performance gap narrows even further after 2012.Q2 when the Fed persistently undershoots its $2 \%$ inflation target. At the end of the data sample in 2017.Q4, the weight $\mu_{t}$ assigned to the targeted forecast rules is 0.68 . In the bottom left panel, the correlation coefficients between the switching model's expected inflation series and the two U.S. data expected inflation series are 0.81 (inflation swaps) and 0.63 (ATSIX), respectively. 
Figure 5: Counterfactual Exercise: Policy Response to Natural Rate Gap

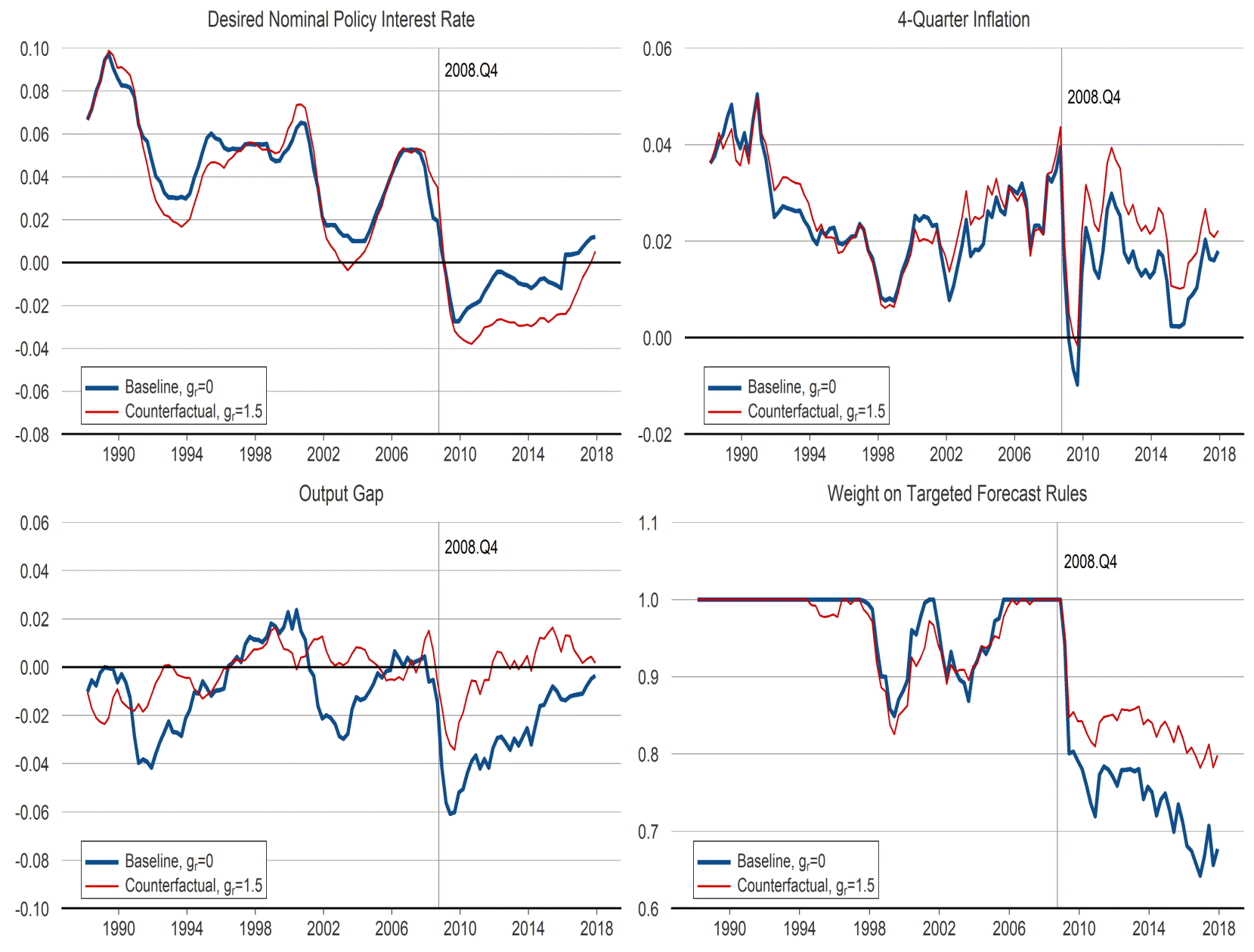

Notes: The counterfactual exercise employs the same initial conditions and the same sequences for $\nu_{t}$, $u_{t}, r_{t}$, and $E_{t} r_{t}^{*}$ as in Figure 4, but the monetary policy rule is now changed to allow for a direct response to the natural rate gap with $g_{r}=1.5$. Relative to the baseline exercise, the counterfactual exercise lengthens the ZLB episode by 7 quarters, but it succeeds in reducing downside fluctuations in the output gap and inflation, thereby increasing the end-of-sample weight $\mu_{t}$ assigned to the targeted forecast rules. 


\section{Figure 6: Distributions of Endogenous Variables}
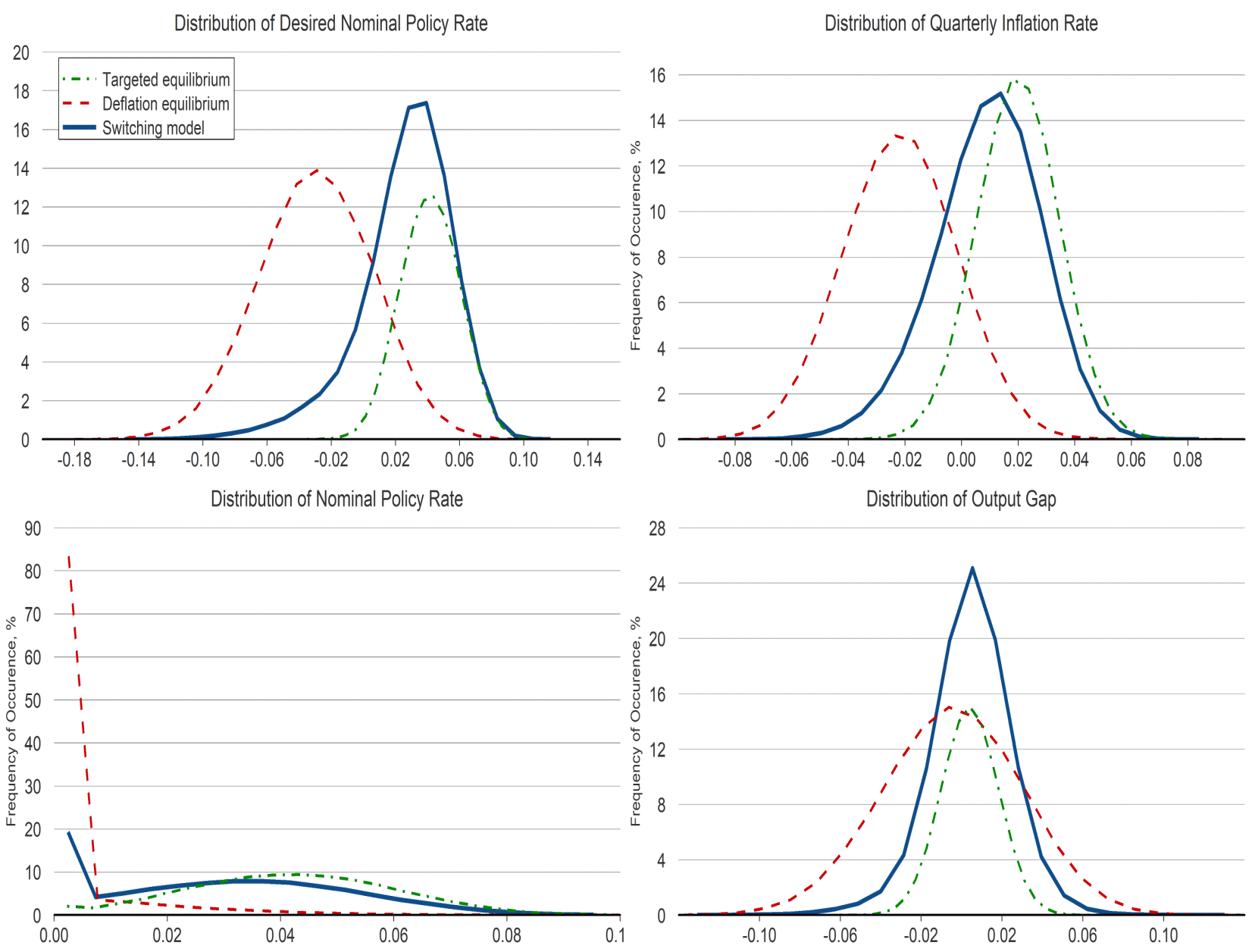

Notes: Model variables in the deflation equilibrium have distributions with lower means but higher variances than those in the targeted equilibrium. But the significant overlap in the various distributions creates a dilemma for an agent who seeks to determine the degree to which a string of recent data observations are drawn from one local equilibrium or the other. The central bank in the switching model undershoots its inflation target and the volatilities of the output gap and inflation are both higher relative to the targeted equilibrium. The bottom right panel shows that the likelihood of a $-6.1 \%$ output gap in the targeted equilibrium is essentially zero. In contrast, a Great Recession-type episode is plausible in the switching model. 
Figure 7: Distributions of ZLB Duration

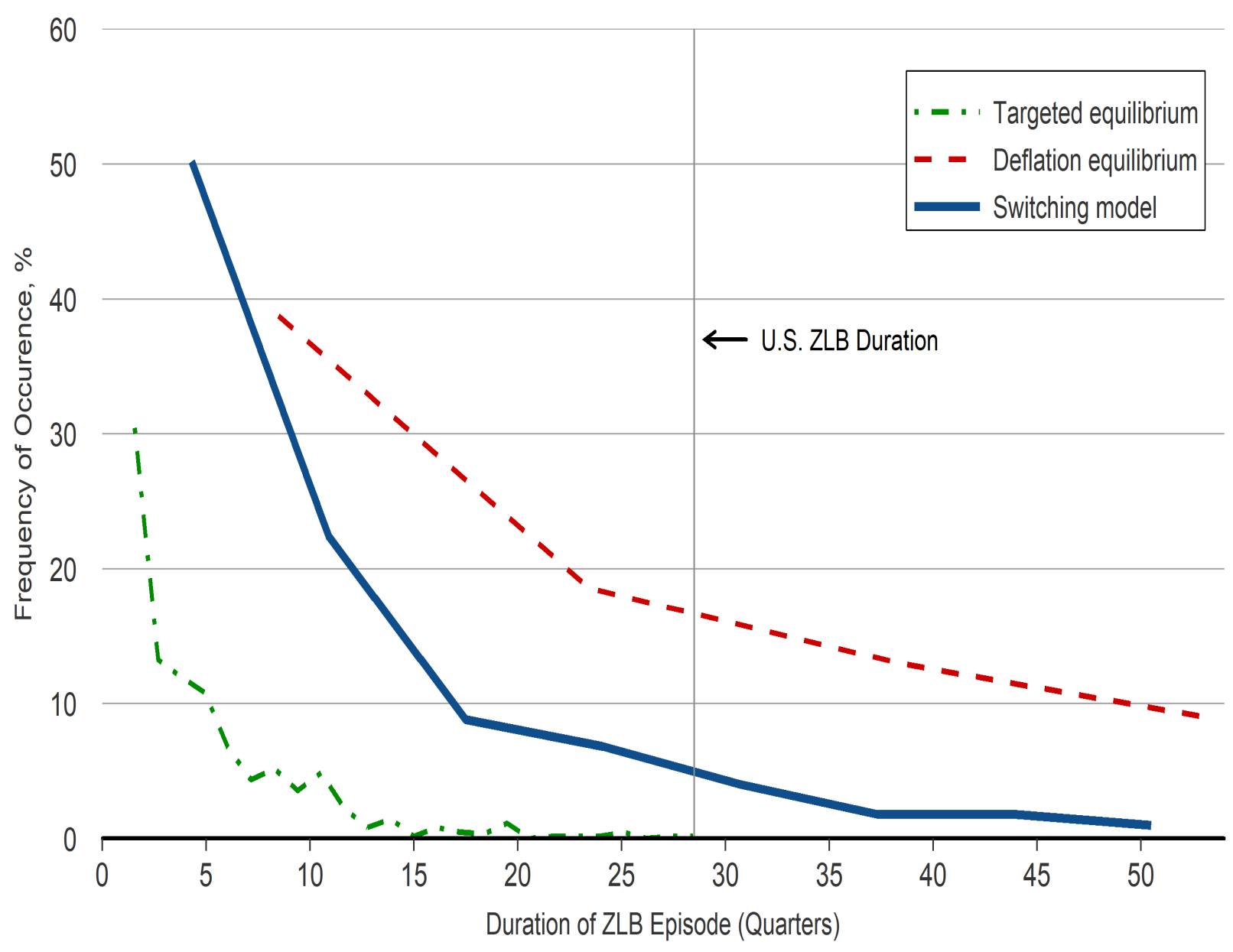

Notes: Unlike the targeted equilibrium, the switching model can produce infrequent but long-lived ZLB episodes in response to small, normally distributed shocks. A 29 quarter ZLB episode (the duration observed in U.S. data since 1988) is an extremely rare event in the targeted equilibrium but can occur with about $5 \%$ frequency in the switching model. 